\title{
Facile synthesis of hard carbon microspheres from polyphenols for sodium-ion batteries: insight into local structure and interfacial kinetics
}

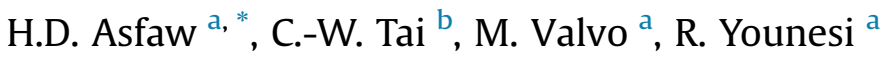 \\ a Department of Chemistry-The Ångström Laboratory, Uppsala University, Lägerhyddsvägen 1, Box 538, 75121, Uppsala, Sweden \\ b Department of Materials and Environmental Chemistry, Arrhenius Laboratory, Stockholm University, SE-10691, Stockholm, Sweden
}

\section{A R T I C L E I N F O}

\section{Article history:}

Received 31 March 2020

Received in revised form

14 August 2020

Accepted 17 August 2020

Available online 26 August 2020

\section{Keywords:}

Resorcinol-formaldehyde

Disordered carbon

Prussian white

Rate performance

Sodium-ion battery

\begin{abstract}
A B S T R A C T
Hard carbons are the most promising negative active materials for sodium ion storage. In this work, a simple synthesis approach is proposed to produce hard carbon microspheres (CMSs) (with a mean diameter of $\sim 1.3 \mu \mathrm{m}$ ) from resorcinol-formaldehyde precursors produced via acid-catalyzed polycondensation reaction. Samples prepared at 1200,1400 , and $1500{ }^{\circ} \mathrm{C}$ showed different electrochemical behavior in terms of reversible capacity, initial coulombic efficiency (iCE), and the mechanism of sodium ion storage. The specific capacity contributions from the flat voltage profile $(<0.1 \mathrm{~V})$ and the sloping voltage region $(0.1-1 \mathrm{~V})$ showed strong correlation to the local structure (and carbonization temperature) determined by the interlayer spacing $\left(\mathrm{d}_{002}\right)$ and the Raman $\mathrm{I}_{\mathrm{D}} / \mathrm{I}_{\mathrm{G}}$ ratio of the hard carbons $(\mathrm{HCS})$ and the rate of cycling. Electrochemical tests indicated that the $\mathrm{HC}$ synthesized at $1500{ }^{\circ} \mathrm{C}$ performed best with an iCE of $85-89 \%$ and a reversible capacity of $300-340 \mathrm{mAh} \mathrm{g}-1$ at $10 \mathrm{~mA} \mathrm{~g}^{-1}$, with the majority of charge stored below $0.1 \mathrm{~V}$. The $\mathrm{d}_{002}$ and the $\mathrm{I}_{\mathrm{D}} / \mathrm{I}_{\mathrm{G}}$ ratio for the sample were $\sim 3.7 \AA$ And $\sim 1.27$, respectively, parameters indicative of the ideal local structure in HCs required for optimum performance in sodiumion cells. In addition, galvanostatic tests on three-electrode half-cells cells revealed that sodium metal plating occurred as cycling rates were increased beyond $80 \mathrm{~mA} \mathrm{~g}^{-1}$ leading to considerably high capacity and poor coulombic efficiency, a point that must be considered in full-cell batteries. Pairing the hard CMS electrodes with Prussian white positive electrode, a proof-of-concept cell could provide a specific capacity of almost $100 \mathrm{mAh} \mathrm{g}^{-1}$ maintained for more than 50 cycles with a nominal voltage of $3 \mathrm{~V}$.

(C) 2020 The Author(s). Published by Elsevier Ltd. This is an open access article under the CC BY license
\end{abstract}

(http://creativecommons.org/licenses/by/4.0/).

\section{Introduction}

Prospects of building more sustainable society that is less reliant on fossil fuels have inspired research into a wide range of energy storage systems. Lithium-ion batteries (LIBs) are by far the most mature technology in current use. The scale of utilization of LIBs in the future may be hampered by the scarcity of lithium-containing minerals, unless extensive recycling efforts are pursued [1]. To complement LIBs, alternative battery systems based on sodium, potassium, and multivalent cations should be developed [2]. In this context, sodium-ion batteries (SIBs) have emerged as the most promising alternative energy storage systems due to the abundance and widespread distribution of sodium-bearing minerals in the

\footnotetext{
* Corresponding author.

E-mail address: habtom.desta.asfaw@kemi.uu.se (H.D. Asfaw).
}

globe $[3,4]$. Research on SIBs has, to date, focused on the development of active materials and electrolytes that meet the requirements for safety, low environmental impact, sustainability and abundance, long cycle life, and high energy and power densities. One of the bottlenecks for commercial success of SIBs is the lack of negative electrode materials that can deliver stable performance in full-cell batteries with extended lifetime [5-7]. Unlike its success in LIBs, graphite does not form thermodynamically stable intercalation compounds with sodium due to the weak sodiumcarbon interactions leading to unfavorable energetics [8-10]. Unless assisted by high pressure or solvent cointercalation, sodium intercalated graphite provides around $35 \mathrm{mAh} \mathrm{g}^{-1}$ corresponding to the formation of $\mathrm{NaC}_{64}$ composition, as opposed to $\mathrm{LiC}_{6}$ and $\mathrm{KC}_{8}$ compositions for lithium and potassium ion intercalation, respectively [11-13]. The formation of ternary graphite intercalation compounds (GICs) as a result of solvent cointercalation, particularly in electrolytes based on ethers and dimethyl sulfoxide, has been 
exploited to increase the capacity to above $100 \mathrm{mAh} \mathrm{g}^{-1}$ [14-20]. However, the low capacity and poor coulombic efficiency make ternary sodium GICs less attractive [7]. In addition, the solvent molecules trapped within the graphite structure are prone to reductive decomposition and can cause severe graphite exfoliation during long-term cycling [11].

Non-graphitizable carbon materials, variously known as hard carbons (HCs), are structurally suited for storing more sodium ions than graphite and are hence promising for use in future SIBs [21-23]. Hard carbons are characterized by atomic structures consisting of stacks of graphene layers with interlayer spacings ranging from 3.4 to $4 \AA$, large enough to accommodate sodium ions [23-27]. The fragments of crystallites are usually $<50 \AA \AA$ in lateral size $[21,23,24]$ and randomly oriented giving rise to nanopores that are rich in defects such as $\mathrm{sp}^{3}$ and localized $\mathrm{sp}^{2}$ hybridized carbons which likely act as sodium trapping sites [28]. Electrochemical performance of HCs is further influenced by particle morphology, surface area, pore microstructures, degree of graphitization, and heteroatom defects [24,29-33]. These characteristics affect the capacity and mechanism of $\mathrm{Na}^{+}$storage in HCs and are dependent on the materials used as carbon precursors [26]. Cross-linked aromatic polymers with low oxygen content are potentially attractive to prepare HCs with low surface areas and spherical morphologies [34,35,35-41]. Notably, polyphenols synthesized via condensation reactions of phenols with aldehydes in alkaline media can be carbonized to obtain carbon microspheres (CMSs) in quantitative amounts. [42,43,44], Other methods used to synthesize carbon spheres include chemical vapor deposition, arc discharge, laser ablation, and hydrothermal carbonization of biomass $[35,38,41,44-50]$. It should, however, be noted that most of these synthesis approaches are not suited for large-scale and costeffective production of hard CMS for use in commercial batteries.

In this article, acid-catalyzed sol-gel process is pursued to produce resorcinol-formaldehyde (RF) polymer precursors for CMSs. The synthesis approach is considerably faster than the extended Stöber method [42] conventionally used to prepare spherical carbon particles and is scalable. Pyrolysis of the polymeric precursors was carried out at $1200-1500^{\circ} \mathrm{C}$ in Ar atmosphere to produce hard CMSs. The choice of temperature was driven by data gleaned from publications. Accordingly, the optimum carbonization temperature for high specific capacity and initial coulombic efficiency (iCE) ranges from 1200 to $1600{ }^{\circ} \mathrm{C}$ as shown in Fig. 1. A suite of tools including electron microscopy, spectroscopy, and gas adsorption is used to gain insight into the microstructures and atomic structure of the HCs before electrochemical testing. Prototype pouch cells were used to investigate the electrochemical characteristics in both half- and full-cell configurations.
Based on electrochemical data from 3-electrode measurements and electrochemical impedance analysis, efforts are made to assess the true kinetics of sodium ion insertion in spherical HCs. Two types of three-electrode cell designs were investigated for in-depth understanding of ion insertion kinetics and metal plating at high rate cycling. In the first instance, cell impedance was measured on a cell consisting of a working electrode based on Prussian white (PW) cathode, $\mathrm{HC}$ as the counter electrode, and a sodium metal disk serving as the reference electrode. By measuring the impedance for different combinations of electrode, the impedance contribution of the HC electrode can be assessed in isolation from the others. This systematic study is particularly essential in full-cell SIBs in which $\mathrm{HC}$ materials are used in the negative electrode. Second, a threeelectrode cell, with HC acting as a working electrode and two sodium metal electrodes acting as separate counter and reference electrodes, was used to evaluate the rate of $\mathrm{Na}^{+}$insertion without the significant contribution from ohmic drop due to the resistive sodium metal counter electrode. Finally, a preliminary investigation into the potential application of the hard CMSs in SIBs is performed in association with PW positive electrodes, which are considered attractive for use in commercial cells [51,52].

\section{Experimental section}

\subsection{Materials and synthesis}

All chemicals were used as received. To synthesize the polymeric precursor, resorcinol and formaldehyde were reacted in the presence of concentrated $\mathrm{HCl}$ catalyst. In a typical synthesis, $2.2 \mathrm{~g}$ (20 mmol) of resorcinol (Fluka $\left.{ }^{\circledR}\right)$ and $3 \mathrm{~mL}(40 \mathrm{mmol})$ of $37 \%$ formaldehyde (Sigma-Aldrich ${ }^{\circledR}$ ) were mixed thoroughly in $10 \mathrm{~mL}$ of deionized water at room temperature. Then, $3 \mathrm{~mL}$ of concentrated $\mathrm{HCl}$ (Sigma-Aldrich ${ }^{\circledR}$ ) was added dropwise and carefully while stirring. The reaction is highly exothermic, and extreme precautions are advised. Upon completion of the reaction, about $40 \mathrm{~mL}$ of deionized water was added, and the resulting pink precipitate was allowed to settle down. A synopsis of the reaction is provided in Scheme 1 together with a proposed reaction mechanism. Then, the supernatant solution was removed, and the precipitate was repeatedly washed with deionized water and finally dried at $80^{\circ} \mathrm{C}$. A sample of the RF polymer powder was placed in an alumina crucible and carbonized in a tube furnace (Entech ${ }^{\circledR}$ with Eurotherm ${ }^{\circledR}$ controller) at 1200,1400 , and $1500{ }^{\circ} \mathrm{C}$ for $1 \mathrm{~h}$ under a continuous flow of Ar gas to obtain hard CMSs, which will henceforth be referred to CMS-1200, CMS-1400, and CMS-1500, respectively.
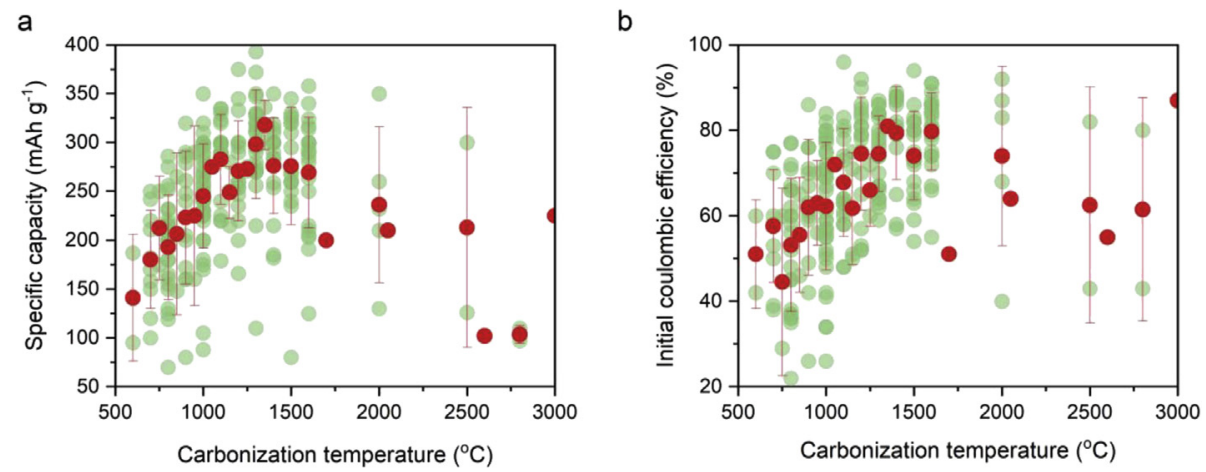

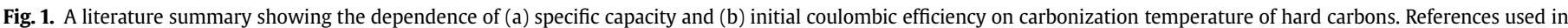

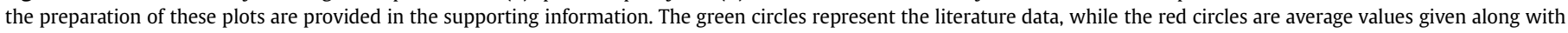
the corresponding standard deviations. 


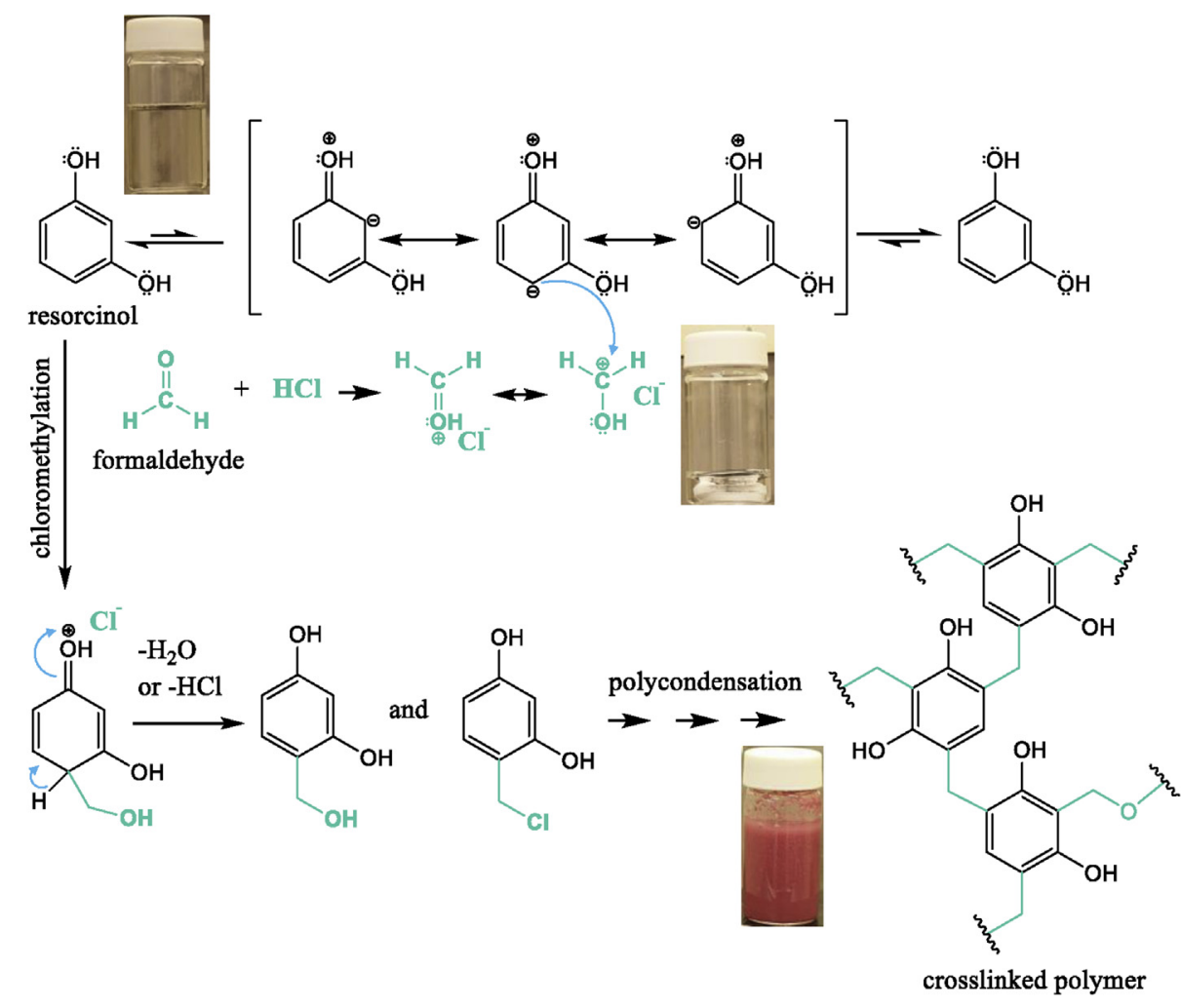

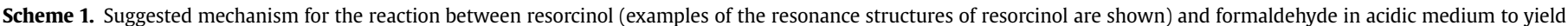

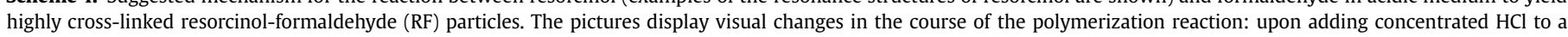
solution of resorcinol and formaldehyde, a pink precipitate formed.

\subsection{Characterization techniques}

\subsubsection{Fourier transform infrared spectroscopy}

Attenuated total reflectance Fourier transform infrared spectroscopy (FTIR) spectrometer (PerkinElmer ${ }^{\circledR}$ ) was used to identify structural features of the polymer precursor and the HC derived therefrom.

\subsubsection{Thermogravimetric analysis}

Pyrolysis and carbonization of the RF polymers were investigated under nitrogen gas using Q500 TGA $1000^{\circ} \mathrm{C}$ (TA Instruments). About $4.5 \mathrm{mg}$ of the polymer powder was placed in an alumina crucible and heated to $1000{ }^{\circ} \mathrm{C}$ at a rate of $5^{\circ} \mathrm{C} \mathrm{min}-1$.

\subsubsection{Scanning electron microscopy}

The powder was spread on a carbon tape (Agar Scientific ${ }^{\circledR}$ ) which was mounted on an aluminum stub. To get rid of loosely attached particles, nitrogen gas was carefully blown over the sample. The microstructures and morphologies of the CMSs were studied using Zeiss ${ }^{\circledR}$ Merlin scanning electron microscopy (SEM) instrument. All imaging was carried out at a working distance of $7 \mathrm{~mm}$ using a $5 \mathrm{keV}$ electron beam, a probe current of $100 \mathrm{pA}$ and collecting secondary electrons with the InLens and the HE-SE2 detectors.

\subsubsection{Transmission electron microscopy}

A powder sample was dispersed in ethanol and sonicated in preparation for transmission electron microscopy (TEM) analysis. A drop of the dispersion was placed on the TEM grid and dried. TEM imaging and electron energy-loss spectroscopy (EELS) were carried out in the $200 \mathrm{kV}$ field emission JEOL ${ }^{\circledR} 2100 \mathrm{~F}$ microscope. The selected-area electron diffraction (SAED) and TEM images were recorded by a Gatan Orius 200D and Ultrascan 1000 XP camera, respectively. The EELS spectra were taken in TEM image mode by Gatan Imaging Filter (GIF Tridiem 863). Deconvolution of the lowloss features and power law model background subtraction were applied to extract the EELS edges in the spectra. Reference spectra of graphite were obtained from the EELS database https://eelsdb. eu/spectra/graphite/ [53].

\subsubsection{X-ray photoelectron spectroscopy}

The X-ray photoelectron spectroscopy (XPS) measurements were performed on a $\mathrm{PHI}{ }^{\circledR} 5500$ spectrometer equipped with a monochromatic $\mathrm{Al} \mathrm{K} \alpha$ radiation $(1487 \mathrm{eV})$ emitted at an angle of $45^{\circ}$. A sample of the powder was placed on a copper tape and blown over with nitrogen gas to remove loose particles.

\subsubsection{Raman spectroscopy}

The Raman spectrum of CMSs was collected on a Raman spectrometer (Renishaw InVia Raman Microscope) using a $50 \mathrm{~mW} 532$ $\mathrm{nm}$ solid-state laser operated at $0.5 \%$ power. Peak fitting was performed using pseudo-Voigt functions based on the RamPy Python library developed by Losq [54].

\subsubsection{Specific surface area analysis by $\mathrm{N}_{2}$-gas physisorption}

Evaluation of the porosity and the Brunnauer-Emmett-Teller (BET) specific surface areas (SSA) of the carbon sample was conducted using $\mathrm{N}_{2}$-gas physisorption at $77 \mathrm{~K}$ using an ASAP2020 analyzer (Micromeritics ${ }^{\circledR}$ ). The sample (about $0.14-0.2 \mathrm{~g}$ powder) was degassed at $80^{\circ} \mathrm{C}$ under $20 \mu \mathrm{mHg}$ for about $4 \mathrm{~h}$ and at $250{ }^{\circ} \mathrm{C}$ under $20 \mathrm{mmHg}$ for $6 \mathrm{~h}$ before analysis. 


\subsubsection{Electrode fabrication and electrochemical testing}

To fabricate the electrodes, a slurry was prepared by mixing $94 \%$ by weight of CMS powder and 6\% of CMC binder (Leclanché ${ }^{\circledR}$ ) in a mixture of deionized water and absolute ethanol in a 9:1 ratio by volume. The mixture was homogenized to a slurry consistency on a vortex homogenizer (Vortex ${ }^{\circledR}$ Genie2 from Scientific Industries) and then cast onto a carbon-coated aluminum foil using a bar coater (RK Control Coater) and a doctor blade applicator (ZFR 2040, Zehntner ${ }^{\circledR}$ testing instruments) to set the thickness to $50 \mu \mathrm{m}$. The coating was dried at ambient conditions, and $13-\mathrm{mm}$ disk electrodes were punched out using a perforator (Hohsen ${ }^{\circledR}$ electrode puncher). All electrodes were dried before use in electrochemical cells at $120^{\circ} \mathrm{C}$ for $12 \mathrm{~h}$ in a vacuum oven (Büchi® ${ }^{\circledR}$ Glass Oven B-585) and stored in a glovebox (GS® Glovebox Systemtechnik) with both $\mathrm{O}_{2}$ and $\mathrm{H}_{2} \mathrm{O}$ levels maintained at about $0.2 \mathrm{ppm}$. The PW electrodes (supplied by Altris ${ }^{\circledR} A B$ ) were prepared in the same way, except that the composition was $85 \%$ PW, $10 \%$ Super P (Alfa Aesar ${ }^{\circledR}$ ) carbon additive, and 5\% CMC (Leclanché ${ }^{\circledR}$ ) binder. Pouch cells were then assembled using these electrodes and sodium metal disks in twoand three-electrode half-cell configurations. For impedance measurements, three-electrode full-cells were constructed using the hard CMSs as electrodes and PW positive electrodes together with a sodium metal disk acting as a dedicated reference. In all the cells, glass fiber separators ( $240 \mu \mathrm{m}$ in thickness, Whatman $\left.{ }^{\circledR}\right)$ impregnated with $100-200 \mu \mathrm{L}$ electrolyte composed of $1 \mathrm{M} \mathrm{NaPF}_{6}$ (Stella Chemifa $\left.{ }^{\circledR}\right)$ in 1:1 volume ratio of ethylene carbonate and diethyl

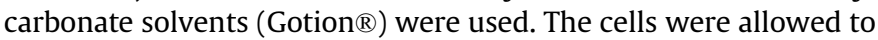
relax at open circuit voltage (OCV) for $12 \mathrm{~h}$ before starting the actual electrochemical testing. Cyclic voltammetry (CV) and galvanostatic tests were conducted on Bio-Logic $₫$ MPG2 potentiostats and Arbin BTS cyclers in the voltage ranges from 0.005 (or 0 ) $\mathrm{V}$ to 2 (or 2.5) $\mathrm{V}$ for $\mathrm{HC}$ and $1.0-3.8 \mathrm{~V}$ vs. $\mathrm{Na}^{+} / \mathrm{Na}$ for PW. In the galvanostatic tests, specific currents (applied current normalized to the mass of the HC in half-cells and the mass of PW in full-cells) were applied. In constant current-constant voltage (CC-CV) measurements, half-cells were cycled at $10 \mathrm{~mA} \mathrm{~g}^{-1}$ between 0 and $2.5 \mathrm{~V}$ vs. $\mathrm{Na}^{+} / \mathrm{Na}$, with the voltage held at the cutoff values, that is 0 and $2.5 \mathrm{~V}$. The total experiment duration was limited to a maximum of $64 \mathrm{~h}$. In addition, electrochemical impedance spectroscopy (EIS) measurements were conducted using a Bio-Logic MPG2-128 potentiostat on a 2-electrode half-cell (composed of HC working electrode and $\mathrm{Na}$ metal electrode doubling as a counter and reference electrode) and a 3-electrode full-cell (composed of PW working electrode, $\mathrm{HC}$ counter electrode, and Na metal reference electrode) before and after cycling. A sinusoidal signal with a voltage amplitude of $3 \mathrm{mV}$ and a frequency range of $20 \mathrm{kHz}$ to $10 \mathrm{mHz}$ was applied on the cells relaxed to stable (OCV. The electrode configurations used in the measurement are displayed in Fig. S11. For full-cell tests, the mass loading of the HC on 13-mm electrodes was on average $1.34 \mathrm{mg}$ or $1 \mathrm{mg} \mathrm{cm}^{-2}$, and the PW electrodes typically weighed $2.62 \mathrm{mg}$ or $1.93 \mathrm{mg} \mathrm{cm}^{-2}$. In other words, the mass ratio of PW to HC was around 1.93 amounting to a charge ratio of 0.997 (i.e., charge $(\mathrm{PW}) /$ charge $(\mathrm{HC})=(309 \mu \mathrm{Ah}$ $\left.\left.\mathrm{cm}^{-2}\right) /\left(310 \mu \mathrm{Ah} \mathrm{cm}^{-2}\right)\right)$, with the assumption that the average capacity of HC was $310 \mathrm{mAh} \mathrm{g}^{-1}$ and that of PW was $160 \mathrm{mAh} \mathrm{g}$ based on half-cell tests. Details are summarized in Tables S2 and S3.

\section{Results and discussion}

\subsection{Synthesis and structure analyses}

Polymeric materials composed of significant proportions of cross-linked aromatic groups are considered suitable precursors for HCs. A particularly attractive group of materials in this regard is polyphenols such as RF polymers investigated in this article. As described in Scheme 1, reactions of formaldehyde with resorcinol, in the presence of concentrated $\mathrm{HCl}$, proceed via chloromethylation of resorcinol resulting in highly activated aromatic intermediates which further undergo polycondensation reactions [55]. The major products are hypercross-linked aromatic polyphenols, usually known as RF resins. The identification of the chemical nature of the polymer precursor and CMS-1500 is given in the FTIR spectra in Fig. 2 (a). The broad band due to symmetric stretching vibrations of the $-\mathrm{OH}$ functional groups on resorcinol appears at around $\bar{\nu} \sim 3248 \mathrm{~cm}^{-1}$. The bands, due to out-of-plane aromatic $-\mathrm{C}-\mathrm{H}$ deformation vibrations, in the region 900 to $600 \mathrm{~cm}^{-1}$ are sensitive to the number of substituents on the benzene ring, and in this precursor, the band at $\bar{v} \sim 844 \mathrm{~cm}^{-1}$ is characteristic of tetra- and penta-substituted aromatic rings, in agreement with the structure proposed in Scheme 1. In addition, the extensive substitution on resorcinol is evident in the extremely weak band of the aromatic $\mathrm{C}-\mathrm{H}$ stretching vibration at $\bar{v} \sim 3026 \mathrm{~cm}^{-1}$. Typical of aromatic compounds, the band at approximately $\bar{\nu} \sim 1600 \mathrm{~cm}^{-1}$ is attributed to the stretching vibrations of the $-\mathrm{C}=\mathrm{C}$ - bonds in the aromatic rings. There are extremely weak bands in the range 2950 to $2890 \mathrm{~cm}^{-1}$ due to asymmetric and symmetric stretching vibrations of methylene groups. In the range 1475 to $1440 \mathrm{~cm}^{-1}$, there are two bands which can be assigned to methylene deformation vibrations in the $-\mathrm{OCH}_{2}-$ bridges. The weak features in the region from 1400 to $1300 \mathrm{~cm}^{-1}$ may be due to a combination of the $\mathrm{O}-\mathrm{H}$ deformation and $\mathrm{C}-\mathrm{OH}$ bending stretching vibrations. The relatively strong band at about $\sim 1210 \mathrm{~cm}^{-1}$ due to $=\mathrm{C}-\mathrm{O}$ stretching and $-\mathrm{C}-\mathrm{O}-\mathrm{C}-$ asymmetric vibration and the band at $\sim 1085 \mathrm{~cm}^{-1}$ due to the $-\mathrm{C}-\mathrm{O}-\mathrm{C}-$ vibration are characteristic of a benzyl ether functional group. In addition, the band around $1170 \mathrm{~cm}^{-1}$ can be assigned to $\mathrm{O}-\mathrm{H}$ in-plane deformation vibration of phenols, while the out-ofplane deformation vibration mode usually appears in the region from 840 to $740 \mathrm{~cm}^{-1}$ [56,57]. These group frequencies are characteristic of RF whose structure is depicted in Scheme 1. In contrast, the CMS-1500 exhibits no meaningful features in the FTIR spectrum as anticipated for pure $\mathrm{sp}^{2}$-hybridized carbon materials. Based on thermogravimetric analysis (TGA) given in Fig. 2 (b), pyrolysis of the polymeric precursor at $1000{ }^{\circ} \mathrm{C}$ results in a residual yield of about $44 \%$, which is much higher than what most polymers and biomass resources can provide.

The SEM images provided in Fig. 3 (a) and (b) and Fig. S1 reveal the spherical morphology of the hard CMSs, regardless of differences in carbonization temperature. On average, the microspheres measure up to $1.3 \mu \mathrm{m}$ in diameter (Fig. 3 (c)) with some agglomeration to form necking structures as observed in the TEM images in Fig. S2 to S4 (a). Other parameters often used to delineate internal microstructure of carbon materials include BET specific surface areas and pore size distributions, which are assessed based on nitrogen gas physisorption measurements. From the isotherm data in Fig. S5 and summarized in Table 1, increasing carbonization temperature from 1200 to $1500{ }^{\circ} \mathrm{C}$ caused the BET specific surface area to decrease from $\sim 590$ to $144 \mathrm{~m}^{2} \mathrm{~g}^{-1}$. The cumulative pore volume ranged from $\sim 0.02$ to $0.05 \mathrm{~cm}^{3} \mathrm{~g}^{-1}$ with major contributions originating from pores smaller than $10 \mathrm{~nm}$. Apart from particle morphology and pore microstructures, electrochemical behavior of HCs can be influenced by the presence of $\mathrm{sp}^{3}$-hybridized carbon bonds, the size of delocalized $\mathrm{sp}^{2}$-hybridized carbon clusters, the proportion of localized $\mathrm{sp}^{2}$ carbon bonds, the presence of heteroatoms such as oxygen, nitrogen, and sulfur, and other defects. Even the mechanism of ion storage is affected by the presence of heteroatom defects [33]. With a view to gaining further understanding of the local structure in the CMS samples, a highresolution transmission electron microscopy (HRTEM) study was performed. 
a
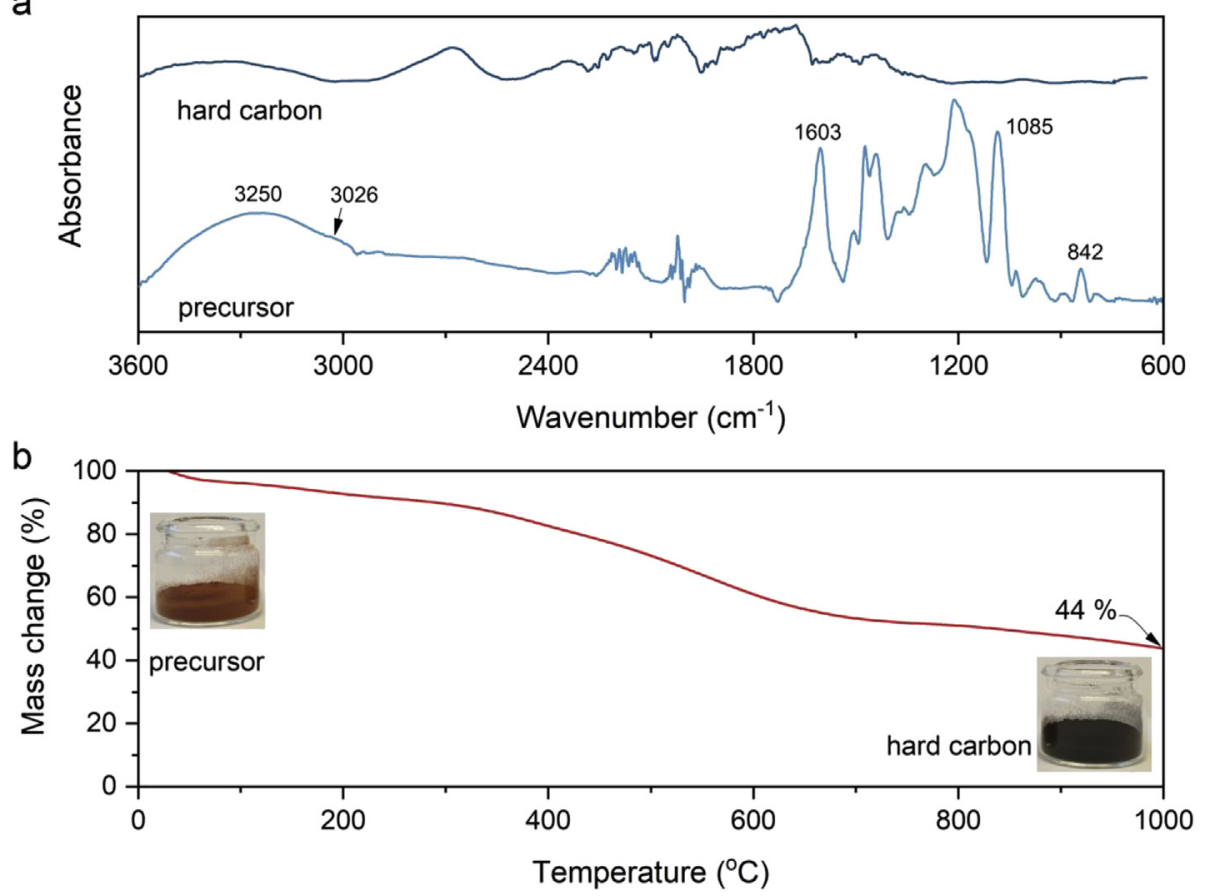

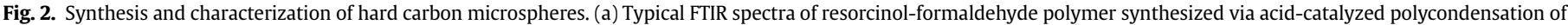

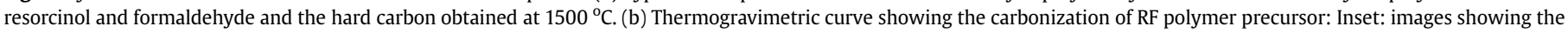
reddish RF precursor and its carbonization to produce hard carbon powder. FTIR, Fourier transform infrared spectroscopy; RF, resorcinol-formaldehyde.

An essential measure of the potential to store sodium ions relies on how further apart the graphene layers, namely the interlayer spacing $\left(\mathrm{d}_{002}\right)$, are in the bulk structure of HCs. The $\mathrm{d}_{002}$ spacing was determined from the HRTEM images in Fig. 3 (d)-(f) and the selected area electron diffraction (SAED) patterns provided in Fig. 3 (g)-(i). As can be seen in the profile intensity plots (Fig. S2 (d) to Fig. S4 (d)) generated in Image [58] from the HRTEM images, the $\mathrm{d}_{002}$ spacing in the CMS samples varies on average from 3.9 to $3.7 \AA$ as the carbonization temperature increased from 1200 to $1500{ }^{\circ} \mathrm{C}$, in agreement with values reported in previous works [23,24,27,59]. Same results were obtained from calculations based on the 002 diffraction rings in the SAED patterns of CMS-1200, CMS-1400, and CMS-1500. A $\mathrm{d}_{002}$ spacing that is much larger than $3.35 \AA$ (in graphite) is generally thought to be favorable for $\mathrm{Na}^{+}$insertion in HCs [59], and thus, the ability to precisely fine-tune this parameter will determine the practical use of HCs in commercial applications. In addition, the SAED rings 100 and 110 indicate that the lattice parameter $a$ is between 2.46 and $2.47 \AA$, which is viewed as a characteristic of $\mathrm{sp}^{2}$-hybridized carbon materials. An estimate of the $\mathrm{C}-\mathrm{C}$ bond distance, $\mathrm{d}(\mathrm{C}-\mathrm{C})$, can be calculated from $a$ to be $1.42 \AA$ using the geometric relationship given by $d(C-C)=a$ / $2 \sin 60^{\circ}$ as illustrated in Fig. S6. The three CMS carbons are as such composed of carbon atoms predominately of $\mathrm{sp}^{2}$ character despite having different $\mathrm{d}_{002}$ spacing and possibly the lateral extent $\left(\mathrm{l}_{\mathrm{a}}\right)$ of coherently scattering $\mathrm{sp}^{2}$-hybridized carbon domains.

Further structural and chemical information was obtained by studying the electron energy absorption characteristics of the carbon atoms as the incident electron beam passes through the bulk of the specimens. The analysis of the energy distribution of electrons that have interacted elastically and inelastically with the carbon specimen is usually shown as the electron energy loss spectra and can be used to obtain electronic structure, chemical nature of the bonds, and the distribution of bond distances around the excited atoms, which are related to the physical properties of the materials [60-62]. The EEL spectra shown in Fig. 4 (a) and (b) display the most common energy loss processes including the zero-loss peak (ZLP), phonon excitation, interband and intraband transitions, plasmon excitations, and inner shell (core level) ionizations. Superimposed on the tailing of the ZLP, there is a feature at around $6.5 \mathrm{eV}$ which is attributed to interband $\pi \rightarrow \pi^{*}$ transitions characteristic of delocalized bonds, such as those in graphite [60]. The progressive shift of these features from $5.4 \mathrm{eV}$ to $6.3 \mathrm{eV}$ (Table 1) as the carbonization temperature increased from 1200 to $1500{ }^{\circ} \mathrm{C}$ is evidence for an increasing order and a decreasing $\mathrm{sp}^{3} / \mathrm{sp}^{2}$ carbon ratio in the CMS samples. In contrast, the spectrum of the amorphous carbon film on the TEM grid, used as a reference here, has no similar feature probably due to presence of a significant proportion of tetrahedrally bonded $\mathrm{sp}^{3}$ carbon atoms which disrupt delocalization of the $\mathrm{sp}^{2}$ carbon bonds. A good measure of the degree of graphitization and order by extension is the plasmon peak position in the EELS spectra. The plasmon peaks arising from the collective oscillation of the $(\sigma+\pi)$ valence electrons [60-63] appear in the range $25-26 \mathrm{eV}$ for the CMS samples, as opposed to $26.8 \mathrm{eV}$ for pristine graphite, and indicate that CMS- 1500 is the most graphitized HC. Insight into the chemical nature of the bonds can be obtained from the core-loss features $\mathrm{C}$ K-edges which originate from excitations of electrons from $1 \mathrm{~s}$ to $\pi^{*}$ and $\sigma^{*}$ states occurring in the range $285-287 \mathrm{eV}$, and $293-294 \mathrm{eV}$, respectively, with the lower limit being for graphite. These features may point to the presence of $\mathrm{sp}^{2}$ and some $\mathrm{sp}^{3}$ hybridized carbon bonds as expected for nongraphitizing carbons which lack long-range order and have commonly been used to determine the $\mathrm{sp}^{3} / \mathrm{sp}^{2}$ carbon contents $[60,63]$. In contrast to the amorphous carbon reference, the CMS specimens exhibited more defined and sharper edges due to $1 \mathrm{~s} \rightarrow$ $\pi^{*}$ transition indicative of the higher proportion of delocalized $\mathrm{sp}^{2}$ carbon structures. Besides, a broad peak due to multiple scattering resonance (MSR) is observed in the $325-330 \mathrm{eV}$ range for graphite and CMS-1500, a feature that is part of the extended energy loss fine structure and is characteristic of the radial distribution of backscattering atoms around the excited carbon atom. The MSR peak 

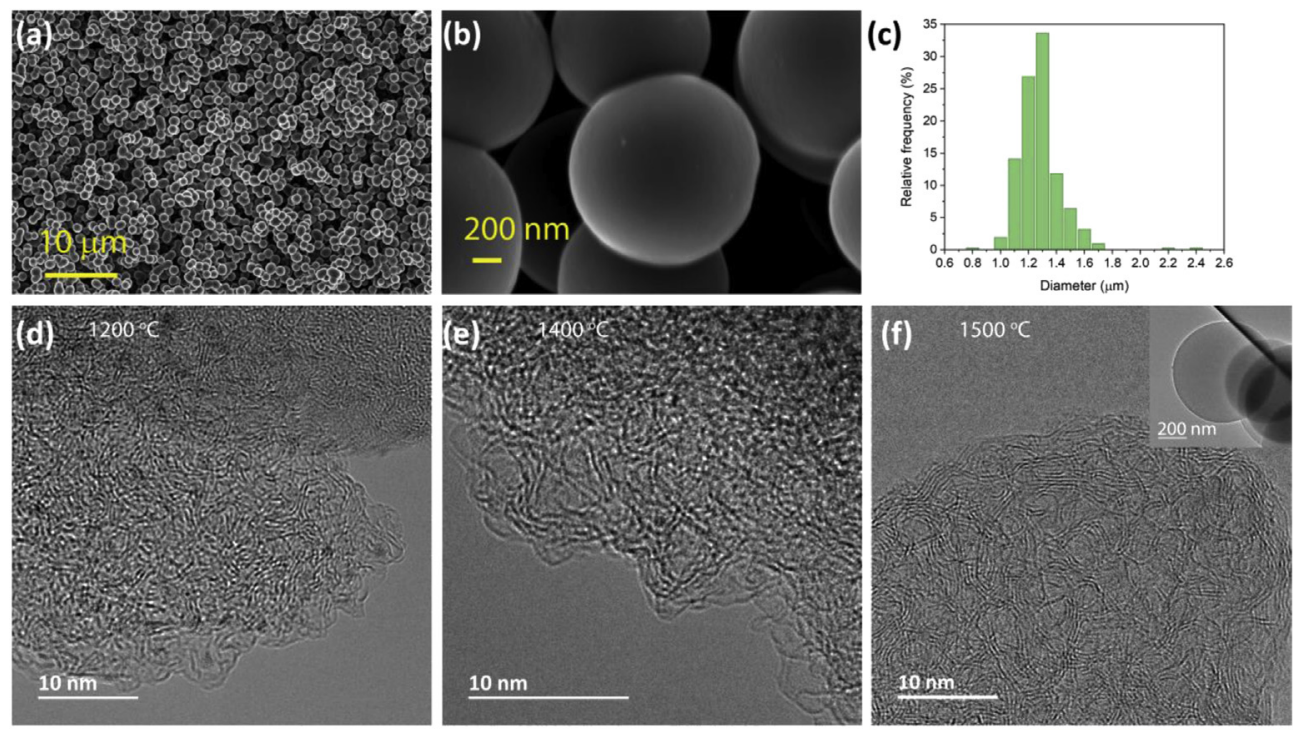

(g) $1200^{\circ} \mathrm{C}$

(h) $1400^{\circ} \mathrm{C}$

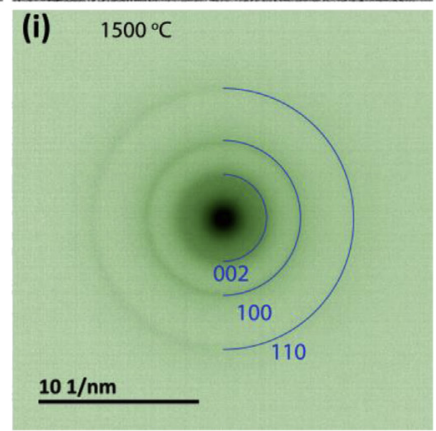

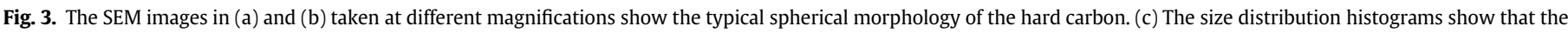

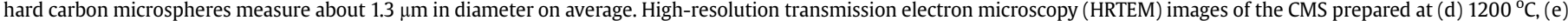

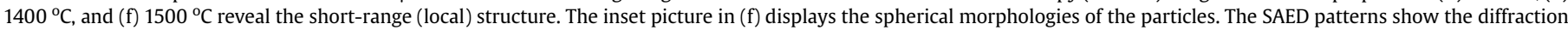
rings 002,100 , and 110 typical of disordered carbon materials for samples obtained at $(\mathrm{g}) 1200{ }^{\circ} \mathrm{C},(\mathrm{h}) 1400{ }^{\circ} \mathrm{C}$, and (i) $1500{ }^{\circ} \mathrm{C}$.

( $\left.\mathrm{E}_{\mathrm{MSR}}\right)$ can be used to estimate the $\mathrm{C}-\mathrm{C}$ bond distance, $\mathrm{d}(\mathrm{C}-\mathrm{C})$ (see Fig. S6), based on the following empirical formulation [60]:

$$
d(C-C)=25.7 \AA \sqrt{e V / E_{M S R}}
$$

with MSR being around $328 \mathrm{eV}$ for CMS-1500, $d(C-C)$ is roughly about $1.42 \AA$ as expected for $\mathrm{sp}^{2}$ carbon bonds, and in good agreement to the values obtained from the electron diffraction pattern. The surface composition of CMS samples was characterized using XPS. The $C 1$ s and 0 1s spectra, given in Fig. 4 (c) and (d) and the wide-scan survey spectra in Fig. S7, indicate that the surface was predominantly composed of carbon atoms of $\mathrm{sp}^{2}$ type (at a binding energy of $284 \mathrm{eV}$ ) along with some oxygen atoms probably bonded to carbon atoms to form carbonyl or ether functional groups $(-532.5 \mathrm{eV})$ or simply physisorbed on the carbon surface.
Finally, Raman scattering of a 532-nm-wavelength excitation laser was conducted to gain insight into the overall structure, type, and clustering of carbon bonds in the three CMS samples. In the Raman spectra provided in Fig. 5, the two most prominent features appearing at $\sim 1340 \mathrm{~cm}^{-1}$ for the $\mathrm{D}$ (defect) band and $\sim 1585 \mathrm{~cm}^{-1}$ for the $\mathrm{G}$ (graphitic) band are characteristic of disordered carbon materials [64-66]. The fitting of the spectra was performed using pseudo-Voigt functions for the peaks (Fig. 5 (b)). The G-band is attributed to in-plane stretching vibrational mode of $\mathrm{sp}^{2}$ carbon bonds with $E_{2 g}$ symmetry $\left(\sim 1580 \mathrm{~cm}^{-1}\right.$ in graphite), while the Dband is attributed to breathing mode of vibration of hexagonal $\mathrm{sp}^{2}$ carbon rings with $\mathrm{A}_{1 \mathrm{~g}}$ symmetry. As carbonization temperature increased from 1200 to $1500^{\circ} \mathrm{C}$, the D-bands got narrower with the full-width-at-half-maximum (FWHM) being 133,117, and $101 \mathrm{~cm}^{-1}$ for CMS-1200, CMS-1400, and CMS-1500, respectively. Such a trend

Table 1

A summary of some characteristics of the hard carbon microspheres and reference materials.

\begin{tabular}{|c|c|c|c|c|c|c|c|c|c|c|}
\hline $\begin{array}{l}\text { Temperature/ } \\
\text { material }\end{array}$ & $\begin{array}{l}\mathrm{d}_{002} \\
(\AA)\end{array}$ & $\begin{array}{l}\mathrm{d}(\mathrm{C} \\
-\mathrm{C}) \\
(\AA)\end{array}$ & $\begin{array}{l}\text { BET SSA }\left(\mathrm{m}^{2}\right. \\
\left.\mathrm{g}^{-1}\right)\end{array}$ & $\begin{array}{l}\text { Pore volume }\left(\mathrm{cm}^{3}\right. \\
\left.\mathrm{g}^{-1}\right)\end{array}$ & $\begin{array}{l}\mathrm{I}_{\mathrm{D}} / \mathrm{I}_{\mathrm{G}} \text { intensity } \\
\text { ratio }\end{array}$ & $\begin{array}{l}\mathrm{I}_{\mathrm{D}} / \mathrm{I}_{\mathrm{G}} \text { integrated area } \\
\text { ratio }\end{array}$ & $\begin{array}{l}\pi \rightarrow \pi^{*} \\
(\mathrm{eV})\end{array}$ & $\begin{array}{l}(\sigma+\pi) \\
(\mathrm{eV})\end{array}$ & $\begin{array}{l}1 \mathrm{~s} \rightarrow \pi^{*} \text { peak } \\
(\mathrm{eV})\end{array}$ & $\begin{array}{l}1 \mathrm{~s} \rightarrow \sigma^{*} \text { peak } \\
(\mathrm{eV})\end{array}$ \\
\hline $\begin{array}{l}\text { Amorphous carbon } \\
\quad \text { film }\end{array}$ & - & - & - & - & - & - & - & 23 & 286 & 294 \\
\hline 1200 & 3.87 & 1.42 & 595 & 0.01 & 1.03 & 2.43 & 5.4 & 25 & 286.6 & 294 \\
\hline 1400 & 3.78 & 1.42 & 520 & 0.05 & 1.07 & 2.06 & 5.7 & 25 & 286.5 & 294 \\
\hline 1500 & 3.70 & 1.426 & 144 & 0.02 & 1.27 & 2.20 & 6.3 & 26 & 286.3 & 294 \\
\hline Graphite & 3.35 & 1.42 & - & - & 0.11 & 0.26 & 6.5 & 26.8 & 285 & 293 \\
\hline
\end{tabular}

BET, Brunnauer-Emmett-Teller. 

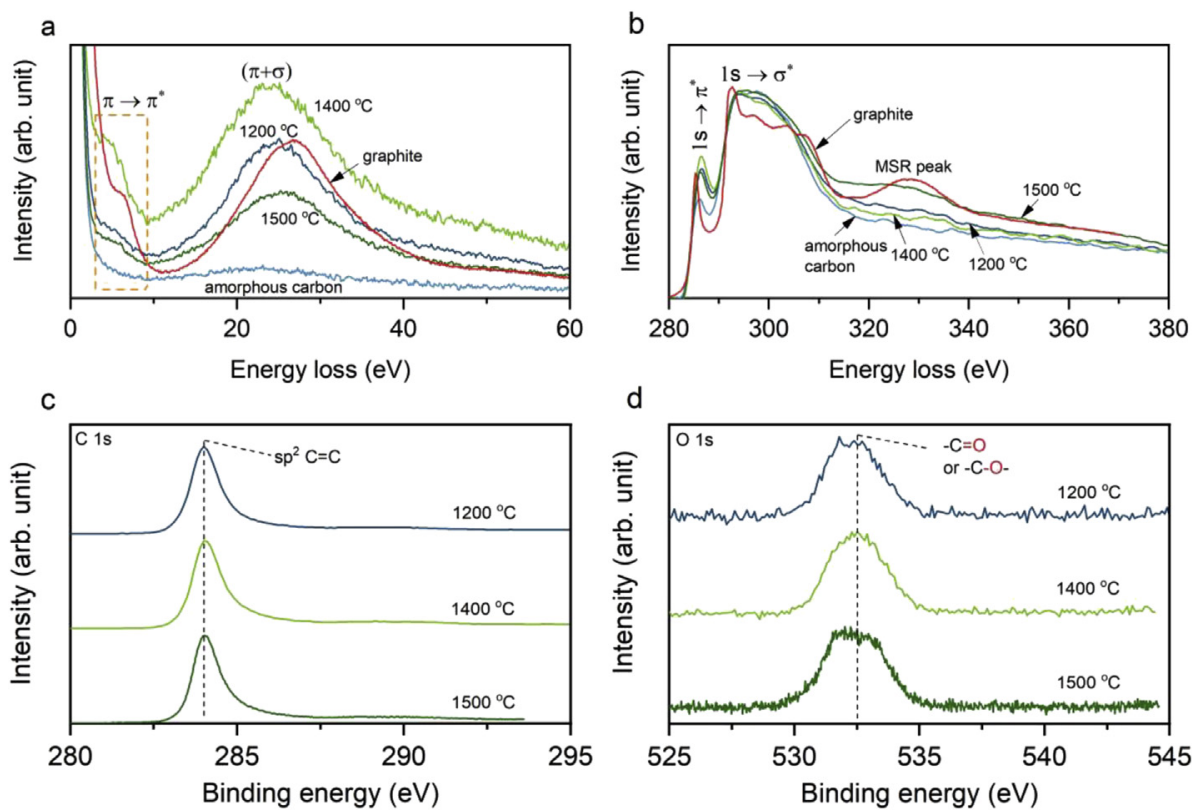

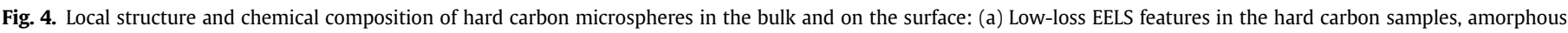

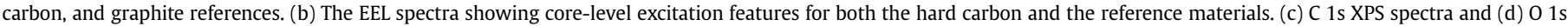
XPS spectra of the hard carbon microspheres showing the presence of mainly carbon and some oxygen atoms on the surface. XPS, -ray photoelectron spectroscopy.

is indicative of the increasing order in the HC local structure with increasing temperature (FWHM for the D-band in graphite is $\left.60 \mathrm{~cm}^{-1}\right)$. In addition, characteristic bands arising from double resonance Raman scattering could be seen between 2400 and $3000 \mathrm{~cm}^{-1}$, particularly in the spectra of graphite and CMS-1500. Other first-order bands designated by $\mathrm{D}_{2}, \mathrm{D}_{3}$, and D' centered, at $\sim 1200 \mathrm{~cm}^{-1}, \sim 1500 \mathrm{~cm}^{-1}$, and $1620 \mathrm{~cm}^{-1}$, respectively, arise from the dispersion of the D- and G-bands as a result of bond distance disorder and distribution and the presence of $\mathrm{sp}^{3}$-hybridized carbons and other defects. The ratio of the intensities of the D- and Gbands, $\left(\mathrm{I}_{\mathrm{D}} / \mathrm{I}_{\mathrm{G}}\right)$, is commonly considered as a measure of the disorder and is correlated to the lateral size of scattering domains $\left(l_{a}\right)$ as $I_{D} / I_{G}$ $=C(\lambda) l_{a}[65,67,68]$. The $\mathrm{I}_{\mathrm{D}} / \mathrm{I}_{\mathrm{G}}$ parameter for CMS-1200, CMS-1400, and CMS-1500 was determined to be $1.03,1.07$, and 1.27 (Table 1 ), respectively, a trend that is indicative of a progressive increase in $l_{a}$ or a decrease in concentration of defects. For the CMS-1500, for example, an $l_{a}$ of $15 \AA$ can be estimated based on the FerrariRobertson relation devised to describe empirical Raman scattering data for disordered carbon materials of various sizes $[64,65]$.

\subsection{Electrochemical characterization}

\subsubsection{The impact of local structure on sodium ion storage in HCS}

The galvanostatic tests performed at $20 \mathrm{~mA} \mathrm{~g}^{-1}$ on the $\mathrm{HC}$ samples are given in Fig. 6 (a) for the first two cycles. The initial discharge/charge capacities of the CMS-1200, CMS-1400, and CMS1500 samples were $296.1 / 204.7,299.5 / 232.6$, and 332.8/281.7 mAh $\mathrm{g}^{-1}$ amounting to iCE of 69,78 , and $85 \%$, respectively. The $\mathrm{Na}^{+}$ insertion (discharge) process during the first cycle is characterized by reductive breakdown of electrolytes forming the solid electrolyte interphase (SEI) layer [69]. The lower iCE of CMS-1200 and CMS-1400 electrodes can, therefore, be attributed to their higher surface areas leading to more electrolyte decomposition during the discharge process. Based on data gleaned from publications (Fig. S8 (c)), the iCE tends, in general, to decrease with increasing BET specific surface areas of HCs, in agreement with the trend observed for the CMS electrodes. In the second cycle, the coulombic efficiencies increase to just above $99 \%$, which was likely due to the formation of the SEI layer that passivated the carbon surface, as
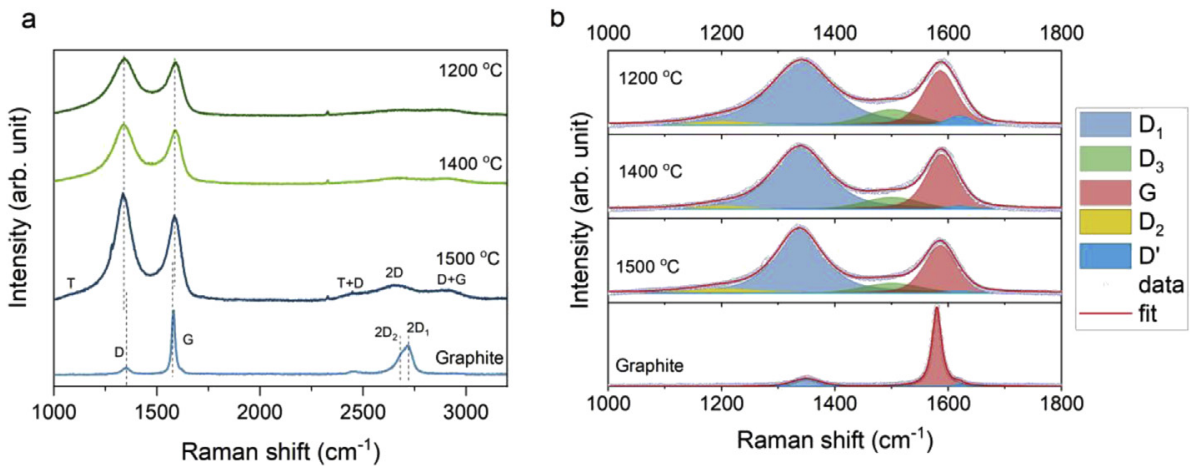

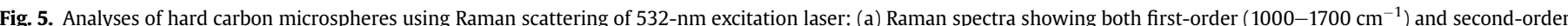

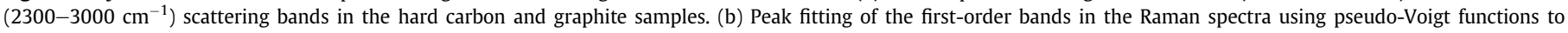
deconvolute the contributions from various $\mathrm{C}-\mathrm{C}$ bond types and vibrational modes. 

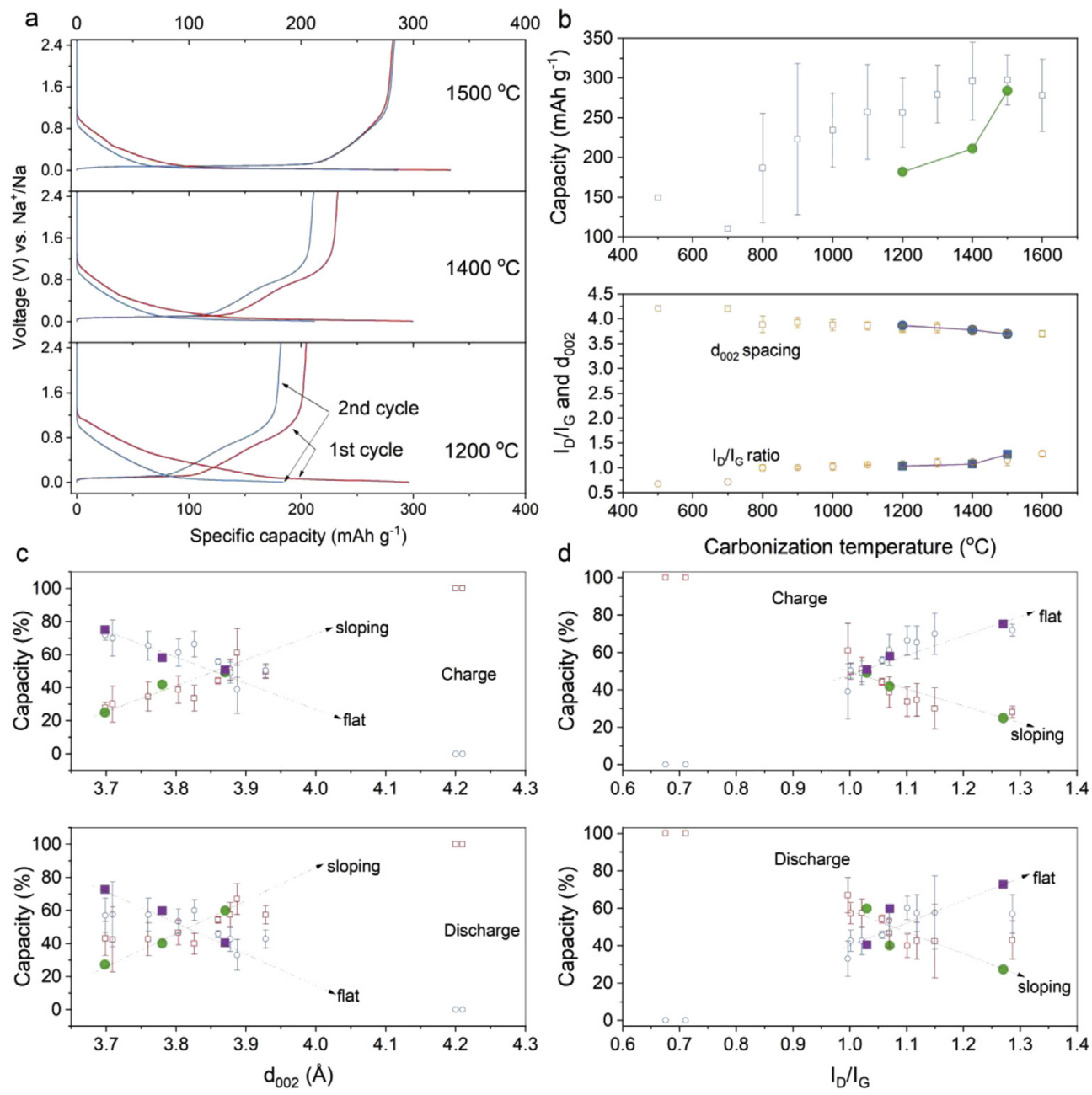

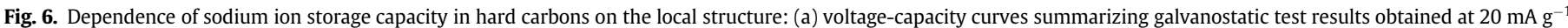

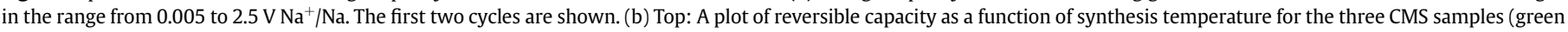

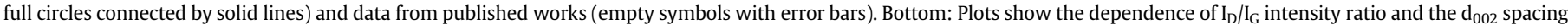

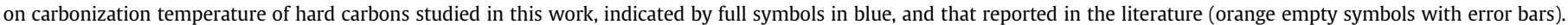

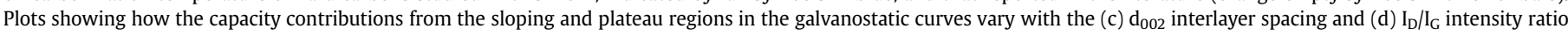

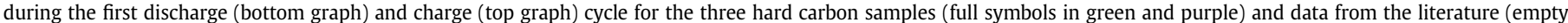
symbols in blue and orange given along with error bars).

anticipated in electrolytes containing $\mathrm{NaPF}_{6}$ in carbonate solvents [77]. Galvanostatic cycling of CMS-1500 at $10 \mathrm{~mA} \mathrm{~g}^{-1}$ gave a slightly improved performance with an iCE of $89 \%$ and a reversible capacity of $300 \mathrm{mAh} \mathrm{g}^{-1}$ (Fig. S9), hinting at the role of kinetics on the performance of the HCs. Further characterization based on the CCCV approach (Fig. S10) was conducted to assess the full sodium ion storage and delivery capacity of CMS electrodes.

In a typical CC-CV measurement on half-cells, the CMS-1500 electrodes were subjected to galvanostatic steps of $10 \mathrm{~mA} \mathrm{~g}^{-1}$ until the cutoff voltages of 0 and $2.5 \mathrm{~V}$ on discharge and charge were attained, at which the cells were held until the current magnitudes decreased to less than $0.2 \mu \mathrm{A}$ (Fig. S10 (a)). The initial cycle was characterized by a coulombic efficiency of nearly $89 \%$ for which the discharge/charge specific capacities were 383.6/341 $\mathrm{mAh} \mathrm{g}^{-1}$ (Fig. S10 (b)). The reversible capacity on the third cycle was about $336 \mathrm{mAh} \mathrm{g}^{-1}$ with a coulombic efficiency of $99.7 \%$. All in all, the hard CMSs performed considerably well as compared with other spherical HCs with similar physical characteristics reported in the literature, as presented in Table S1, and can potentially be used in practical SIBs.

A detailed discussion of the impact of temperature on the performance of the CMS electrodes can be made in terms of the $d_{002}$ spacing and the $\mathrm{I}_{\mathrm{D}} / \mathrm{I}_{\mathrm{G}}$ ratio describing the degree of order in the $\mathrm{HC}$ samples. In addition, extensive analysis of literature data is performed (Fig. 6 (b)-(d), and Fig. S8) to uncover whether the electrochemical behavior of HCs, in general, and the CMS samples, in particular, follows a predictable trend as a function of temperature and material characteristics. A list of references from which the data was retrieved can be found in the Supporting Information. Accordingly, the average reversible capacity increases continuously up until $1500{ }^{\circ} \mathrm{C}$ (reaching $\sim 297 \mathrm{mAh}^{-1}$ ), a trend followed by the CMS samples investigated in this work. At the same time, the $\mathrm{d}_{002}$ decreases from $4.2 \AA$ at $500{ }^{\circ} \mathrm{C}$ to $3.7 \AA$ at $1500{ }^{\circ} \mathrm{C}$, which indicates the increase in ordering (also supported by the increase in $\mathrm{I}_{\mathrm{D}} / \mathrm{I}_{\mathrm{G}}$ ratio) and can be considered optimum for sodium ion storage in HCs [59]. A typical galvanostatic curve of HCs shows two distinct features: a monotonous voltage change in the range from 1 to $0.1 \mathrm{~V}$ and a nearly flat plateau below $0.1 \mathrm{~V}$, which appear at slightly higher voltage on charge. The respective contributions of these regimes to the overall capacity are strongly dependent on the temperature at which the HCs are produced, that is, they are affected by the local structure. Hard carbons prepared at $<1200{ }^{\circ} \mathrm{C}$ seemed to exhibit high discharge capacity with sloping voltage profile (see Fig. S8 (a) and (b)), in which the mechanism of charge 
storage is attributed to surface adsorption and reactions with defects. Electrolyte decomposition starts in this region contributing to the overall irreversible capacity during the initial discharge step. The trend in charge capacity with temperature also shows conclusively that HCs obtained below $1000{ }^{\circ} \mathrm{C}$ have mainly sloping voltage-capacity profiles and are not suitable for use in high-energy SIBs. In Fig. 6 (c) and (d), the variations with $\mathrm{d}_{002}$ spacing and $\mathrm{I}_{\mathrm{D}} / \mathrm{I}_{\mathrm{G}}$ of capacity contributions (given as a percentage of the total capacity) from the sloping and flat voltage profiles of the first cycle galvanostatic curves of CMS-1200, CMS-1400, and CMS-1500 are provided along with literature data. In general, HCs synthesized below $1200{ }^{\circ} \mathrm{C}$ (associated with $\mathrm{d}_{002}$ of $3.86 \AA$ and an $\mathrm{I}_{\mathrm{D}} / \mathrm{I}_{\mathrm{G}}$ ratio of 1.07) are characterized by higher capacity contributions from the sloping region of the galvanostatic curves during discharge and charge processes. Given that most of the irreversible capacity loss during the first discharge occurs in this region, it is imperative to decrease the contributions of charge storage from the sloping voltage profile by optimizing synthesis conditions in interest of increasing the iCE. In this work, further studies are continued with CMS-1500 for which better performance was achieved.

\subsubsection{Interfacial kinetics in 2- and 3-electrode half-cells}

In Fig. 7 (a) and (c), the galvanostatic curves of the first 10 cycles for the hard CMSs cycled in 2-electrode and 3-electrode half-cell configurations are obtained at a specific current of $20 \mathrm{~mA} \mathrm{~g}^{-1}$. In the 3-electrode half-cells, a separate sodium metal foil is used as a reference electrode (Fig. S11 (a)). Perhaps, a striking difference between the two cells is the magnitude of voltage hysteresis, which at $200 \mathrm{mAh} \mathrm{g}^{-1}$ is around $43 \mathrm{mV}$ and $28 \mathrm{mV}$ for the 2- and 3electrode cells, respectively. The increased overpotential in the former case can be attributed to the plating and stripping overpotential of the sodium metal, demonstrating that using it as a combined counter and reference electrode is not viable. Similar observations can be deduced from the differential capacity plots shown in Fig. 7 (b) and (d) for the corresponding galvanostatic curves. In 2-electrode half-cells, the peak-to-peak voltage difference for sodium insertion and removal is $57 \mathrm{mV}$ during the first cycle and $54 \mathrm{mV}$ for the subsequent 9 cycles. However, in the case of the 3-electrode HC-Na cell, the first cycle exhibits a voltage hysteresis of $33 \mathrm{mV}$, while in the subsequent cycles, it decreased to $31 \mathrm{mV}$. The difference is attributed to the overpotential of sodium plating and stripping on the counter electrode as shown in Fig. S12.
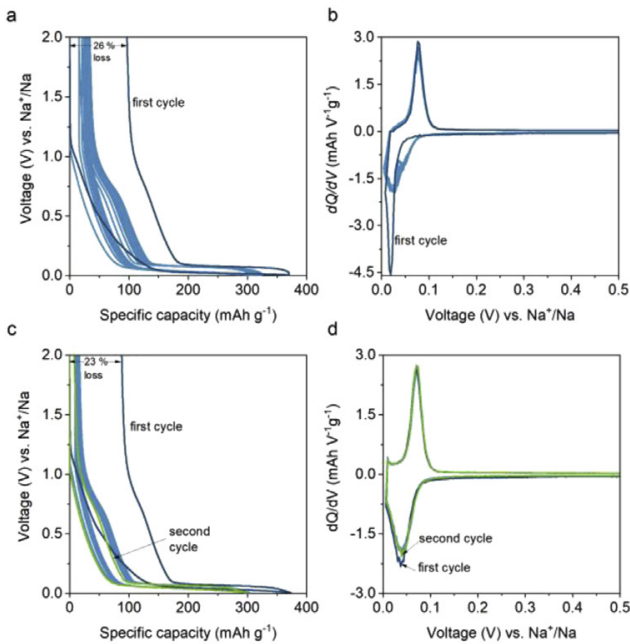

Sodium metal reacts aggressively in carbonate-based electrolytes causing a buildup of decomposition products at the interface which give rise to the SEI layer, and the interfacial resistance increases as a consequence [78]. The cell resistance measured in HC$\mathrm{Na}$ half-cells is essentially dominated by the interfacial resistance at the sodium metal electrode. To better assess the interfacial resistance at the HC electrodes, EIS tests were performed at OCV on a 3electrode full-cell consisting of PW working electrode, HC counter electrode, and Na metal reference electrode before cycling (Fig. 7 (e)) and after cycling (Fig. 7 (f)). The measurements were carried out for the PW vs. Na, HC vs. Na, and PW vs. HC electrode combinations (Fig. S11 (b)). Accordingly, the impedance data measured for the PW vs. HC electrodes indicate largely capacitive behavior typical of porous carbon electrodes. This is indicated in the Nyquist diagram in Fig. 7 (e) by the straight line tilted at $\sim 45^{\circ}$ owing to diffusion-controlled adsorption of ions in the pores at higher frequencies $(20 \mathrm{kHz}-50 \mathrm{~Hz})$ and the more vertical line due to interfacial double layer charging at lower frequencies. In contrast, the impedance data on the PW-Na and HC-Na half-cells exhibited depressed semicircles with the charge transfer resistances being 12 and $13.5 \mathrm{k} \Omega \mathrm{cm}$ [2], respectively. The semicircles are indicative of electron transfer reactions at the $\mathrm{Na}$ metal-electrolyte interface involving electrolyte breakdown and interfacial passivation. Subsequently, the HC electrode is cycled versus the Na metal for 2 cycles to evaluate the change in interfacial resistance and the formation of the SEI layer. The EIS Nyquist diagrams in Fig. 7 (f) show that the charge transfer resistance for HC-Na decreased considerably from $12 \mathrm{k} \Omega \mathrm{cm}^{2}$ before cycling to about $1.4 \mathrm{k} \Omega \mathrm{cm}^{2}$ after cycling. Given that the semicircle is due to the sodium metal, the decrease in resistance can be associated to the plating and stripping steps that removed the passivation layer formed at OCV due to contact with the electrolyte and the working atmosphere. Similar observation was also reported for potassium metal electrodes by Hosaka et al. [79]. These results sufficiently demonstrate the fact that the sodium metal has considerable influence on the cell resistance of half-cells and affects the output voltage, distorts the galvanostatic curves, and suppresses the rate capability of HC electrodes.

\subsubsection{Rate of sodium ion insertion in hard CMSs}

The rate performance of the cells is determined at specific currents ranging from 20 to $1280 \mathrm{mAh} \mathrm{g}^{-1}$ (Fig. 8). At the lowest

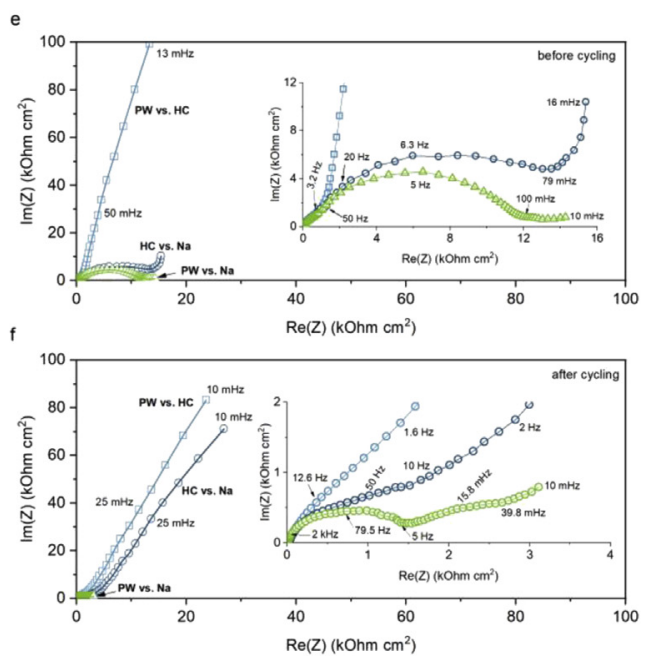

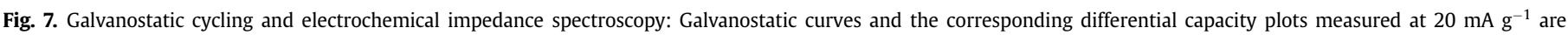

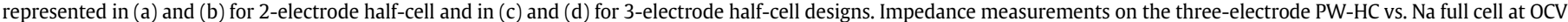

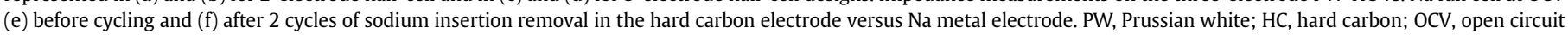
voltage. 
specific current, the cell delivers initial discharge and charge capacities of around 370 and $277 \mathrm{mAh} \mathrm{g}^{-1}$, respectively, amounting to a coulombic efficiency of roughly $75 \%$. In the subsequent 10 cycles, the coulombic efficiency increased to $95,98,98.8$, and $99.5 \%$ for the second, third, fourth, and finally the tenth cycle, respectively. The capacities at the applied specific currents (40-1280 $\mathrm{mA} \mathrm{g}^{-1}$ ) as pointed out earlier (Fig. 8 (a)-(b)) are on average 257 (88.5\%), 185 (63.5\%), 101 (34.8\%), 64 (22\%), 51 (17.5\%), and 41 (14\%) $\mathrm{mAh} \mathrm{g}^{-1}$. Values in brackets show the capacity retention with respect to the lowest rate cycling capacity $\left(291 \mathrm{mAh} \mathrm{g}^{-1}\right)$. Finally, the current is decreased back to $20 \mathrm{~mA} \mathrm{~g}^{-1}$ for which a discharge capacity of up to $304 \mathrm{mAh} \mathrm{g}^{-1}$ with $99.6 \%$ coulombic efficiency was obtained. Furthermore, extended cycling at $80 \mathrm{~mA} \mathrm{~g}^{-1}$ over 150 cycles maintained a capacity retention of $97 \%$ (of the initial capacity: 235 $\mathrm{mAh} \mathrm{g}^{-1}$ ) at the 100th cycle while the coulombic efficiency was nearly $100 \%$ for all cycles. This increase in the coulombic efficiency could be indicative of the cessation of parasitic reactions as a thicker and more stable SEI layer was formed, effectively slowing down reductive decomposition of the electrolyte.

As can be seen in Fig. 7 (a) and (b), the voltage-capacity profiles of HCs typically show monotonous change in the sloping regions from 1 to $0.1 \mathrm{~V}$ and a nearly flat plateau from 0.1 to $0.02 \mathrm{~V}$. On charging, these regions appear in the voltage ranges 0.050 to 0.110 and $0.106-1.2 \mathrm{~V}$, respectively. The charge contributions from the sloping and plateau regions are summarized in Fig. 8 (c). Up until $80 \mathrm{~mA} \mathrm{~g}^{-1}$, the majority of the sodium ion storage capacity originates from the flat voltage regions. The decrease in capacity with increasing cycling currents can be attributed to the ohmic drop due to the interfacial resistance of mainly the sodium metal electrode and the poor mass transport of $\mathrm{Na}^{+}$ions in HCs, whose chemical diffusion coefficients lie in the range $10^{-9}-10^{-16} \mathrm{~cm}^{2} \mathrm{~s}^{-1}$ [80-83]. The majority of capacity at the cycling current $160 \mathrm{~mA} \mathrm{~g}^{-1}$ and higher was due to the sloping voltage region (Fig. S13), an indication that charge storage in this voltage region may involve surfaceconfined processes as in capacitive materials. In contrast, in threeelectrode half-cells, higher capacity retention could be maintained despite the increasing cycling currents. In fact, charge contributions from the flat voltage profile increased dramatically for currents higher than $80 \mathrm{~mA} \mathrm{~g}^{-1}$. As also shown in the differential capacity curves, sodium metal plating was kinetically more favorable than sodium ion insertion as the test currents increased. The specific capacities extended beyond $300 \mathrm{mAh} \mathrm{g}^{-1}$ as a result of contributions from sodium metal plating on the $\mathrm{HC}$ particles. At $320 \mathrm{~mA} \mathrm{~g}^{-1}$, the discharge capacity reaches $713 \mathrm{mAh} \mathrm{g}^{-1}$ while only about 440 $\mathrm{mAh} \mathrm{g}^{-1}$ of the capacity is retrieved on charge amounting to a coulombic efficiency of roughly $62 \%$. Such a trend was not visible in half-cell setups as the resistive loss due to cell impedance narrowed down the working voltage window required for cell operation. Sodium ion insertion in the flat voltage region (Fig. 8 (a)) occurred with slight increase in overpotential as the cycling current increases in contrast to the trend observed in 2-electrode half-cells as shown in Fig. S13. Normally, the overall cell voltage in half-cells includes the overpotential for sodium insertion in HCs and that required for sodium plating and stripping at the counter electrode, which becomes dominant as higher currents are applied, as clearly seen in Fig. S12 and Fig. S14.

\subsubsection{Performance of hard CMSs in full-cell SIBs}

Customarily, the performance of the HC electrode is usually evaluated in half-cell designs in which sodium ions can be supplied in excess and stable cycling can be observed despite the fact that irreversible reactions continue consuming sodium ions. Out of safety concerns related to its high reactivity and due to its poor coulombic efficiency for plating and stripping cycles, sodium metal is an unsuitable counter electrode in carbonate-based electrolytes [78]. The eventual use of HC materials in full-cell SIBs is attractive and is hence considered in this study. The hard CMS (CMS-1500) electrode was paired with $\mathrm{PW}, \mathrm{Na}_{2-\mathrm{x}} \mathrm{Fe}\left[\mathrm{Fe}(\mathrm{CN})_{6}\right]$, positive electrode which is considered promising for application in commercial SIBs $[52,84]$. The PW electrode has a theoretical capacity of $170 \mathrm{mAh} \mathrm{g}^{-1}$ and exhibits two redox couples at around 2.85/3.14 and 3.26/3.33 V with respect to sodium metal (refer the cyclic voltammetry in Fig. S16) that are attributed to redox reactions of the low spin and high spin $\mathrm{Fe}^{2+} / \mathrm{Fe}^{3+}$-containing octahedra in PW, respectively [51]. Both the output voltage and specific capacity are potentially competitive for commercial applications when combined with HC
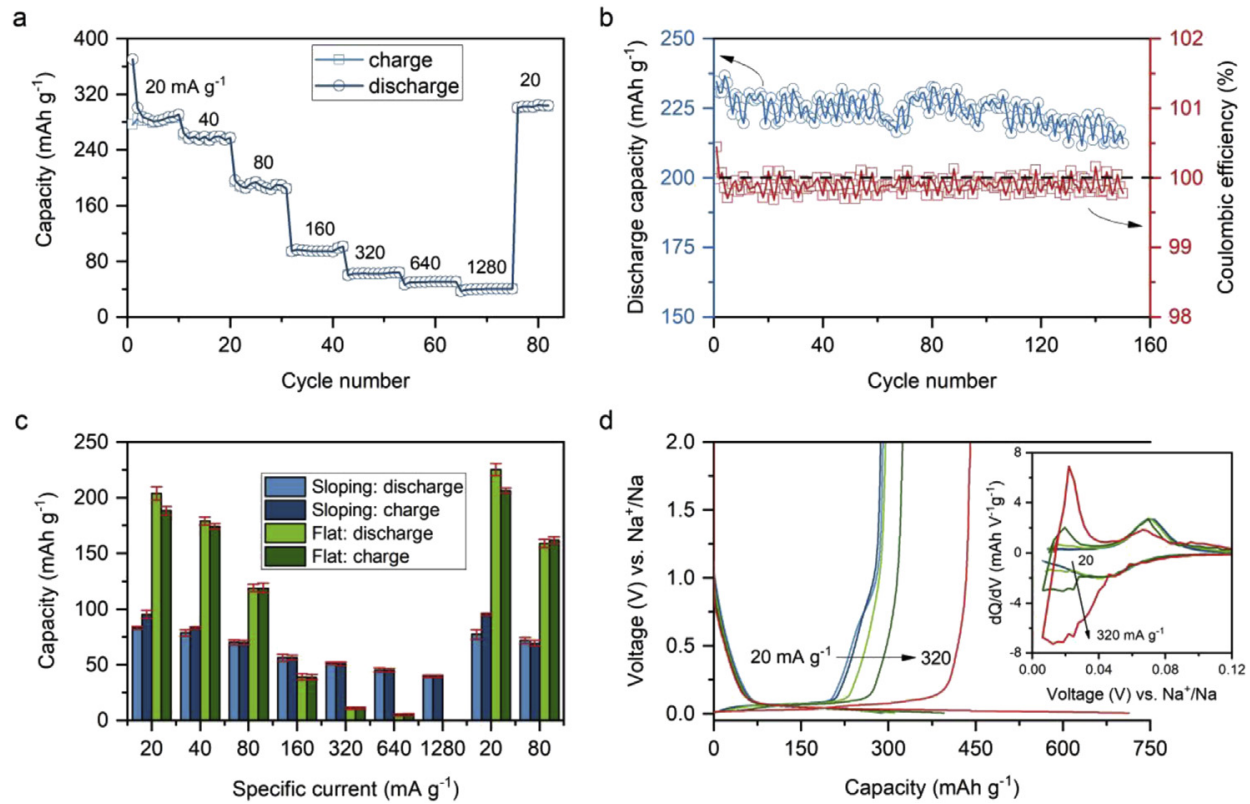

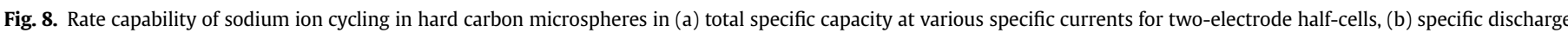

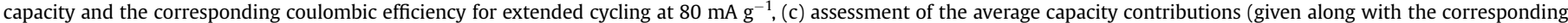

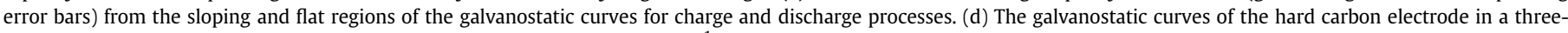
electrode half-cell at selected specific currents $\left(20,40,80,160\right.$, and $\left.320 \mathrm{~mA} \mathrm{~g}^{-1}\right)$ along with the associated differential capacity plots shown in the inset. 

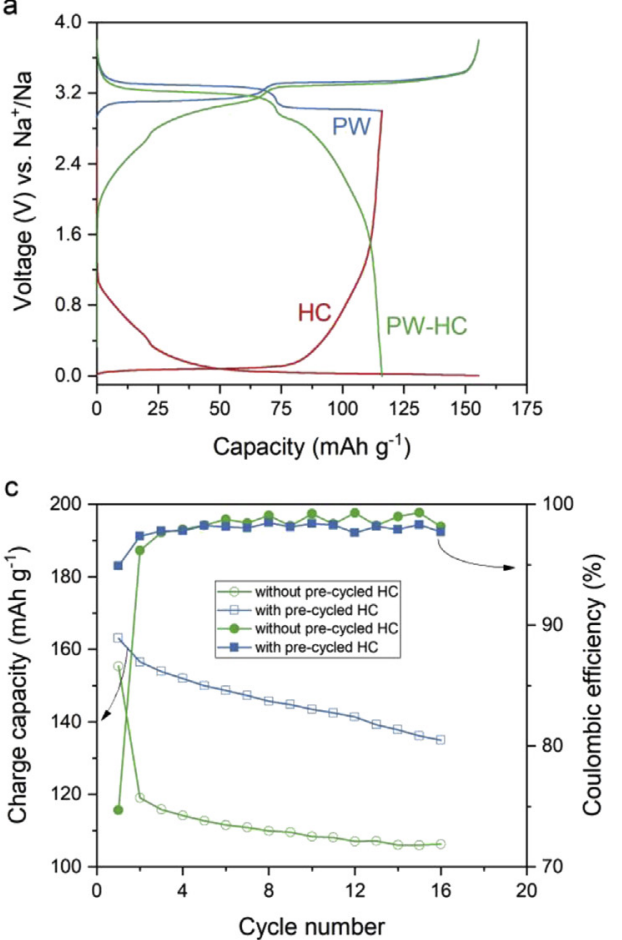

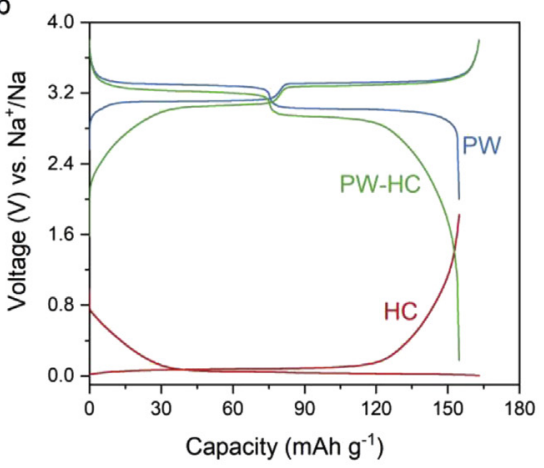

d

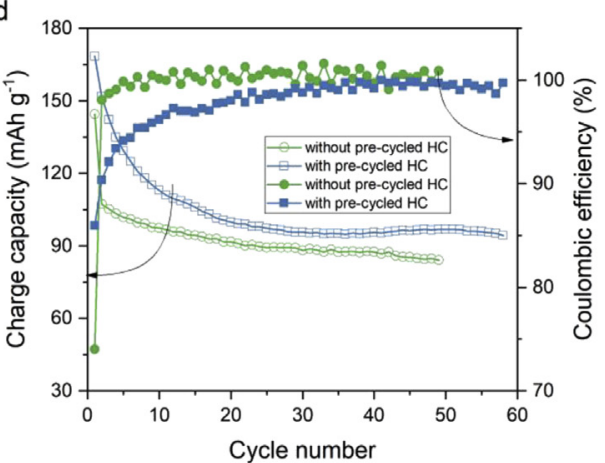

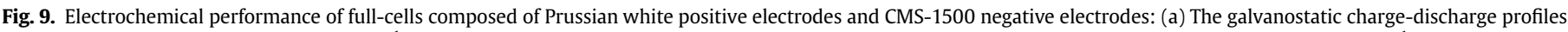

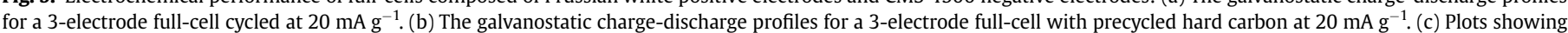

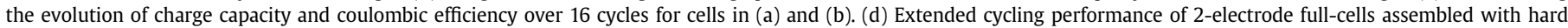
carbon electrodes with and without presodiation step.

electrodes. The output voltage for the full-cell will be in the range 2.7-3.5 V vs. $\mathrm{Na}^{+} / \mathrm{Na}(\sim 3.1 \mathrm{~V}$ on average).

The performance of the hard CMSs in full-cells was assessed using galvanostatic cycling tests as shown in Fig. 9. To assess the impact of the irreversible capacity loss in the HC during the first cycle on the cell performance, galvanostatic tests were conducted on three-electrode cells assembled with HCs with and without presodiation treatments. The first cycle performance exhibited approximately $75 \%$ coulombic efficiency when PW electrodes were paired with the pristine HC electrode (with a PW:HC mass ratio of about 2.1), as observed in Fig. 9a. As per the discussion given in the previous sections, most of the irreversible reaction originates from the HC. It is known that the PW suffers some loss during the first charge-discharge cycle and further capacity fading upon extended cycling; as can be seen in Fig. S15, the PW electrode sustained an 8\% decrease during the first cycle. In the second instance shown in Fig. 9b, the HC was cycled twice versus $\mathrm{Na}$ electrode before being paired with the PW electrode. The iCE in this regard was around $95 \%$, considerably higher than that of the former cell. From the second cycle onwards (Fig. 9c), the coulombic efficiency increased progressively for both cells, but higher specific capacity was maintained in the case of the cell which consisted of precycled HC. Over 15 cycles, the charge capacities of the cells (Fig. 9a and b) decayed to 136 and $106 \mathrm{mAh} \mathrm{g}^{-1}$, respectively, demonstrating that the stable SEI layer on HCs is essential to ensure good performance in full-cells. Further research on electrolyte additives and artificial SEI layers can improve the performance of HCs. Similar trends were observed in 2-electrode full-cells as shown in Fig. 9d. When precycled HC was used, the initial specific capacity of the PW-HC cells was around $168 \mathrm{mAh} \mathrm{g}^{-1}$ for desodiation and $145 \mathrm{mAh} \mathrm{g}^{-1}$ for sodiation corresponding to a coulombic efficiency of $86 \%$. Over 50 cycles (Fig. 9(d)), the discharge capacity drops to about $97 \mathrm{mAh} \mathrm{g}^{-1}$ which amounts to $67 \%$ of the initial capacity. In contrast, the cell with pristine $\mathrm{HC}$ exhibited a $74 \%$ coulombic efficiency during the first cycle and more capacity fading in the subsequent cycles. The capacity loss sustained in the course of long-term cycling in fullcells might be due to loss of sodium ion inventory to irreversible cell reactions both at the positive and negative electrodes. Further optimization of electrode fabrication and electrolyte formulation is needed in future studies to fully unlock the potential of the hard CMSs in SIBs.

\section{Conclusions}

In this study, a simple and fast route to the synthesis of CMSs was developed. A polymeric precursor was synthesized by reacting resorcinol with formaldehyde in acidic aqueous medium. Carbonization of the precursor at 1200,1400 , and $1500{ }^{\circ} \mathrm{C}$ yielded hard CMSs with an average diameter of $1.3 \mu \mathrm{m}$ and a BET specific surface area of 595, 520, and $144 \mathrm{~m}^{2} \mathrm{~g}^{-1}$, respectively. Alhough HRTEM, XPS, and EELS measurements indicate that the CMS samples consist of predominantly $\mathrm{sp}^{2}$-hybridized carbon bonds $(\sim 1.42 \AA$ ) , differences in the degree of graphitization and the interlayer spacing, $\mathrm{d}_{002}$, were observed. From HRTEM images and SAED patterns, the $\mathrm{d}_{002}$ parameter for CMS-1200, CMS-1400, and CMS-1500 was calculated to be on average $3.9 \AA$ A $3.8 \AA$, and $3.7 \AA$, respectively. Apart from the $\mathrm{I}_{\mathrm{D}} / \mathrm{I}_{\mathrm{G}}$ intensity ratio that is commonly used to evaluate the degree of graphitization in carbon materials, the plasmon peak due to $(\sigma+\pi)$ excitations was used to assess the extent of bond delocalization in the specimens. Accordingly, the CMS-1500 was the most graphitized showing a $(\sigma+\pi)$ peak at around $26.3 \mathrm{eV}$, as opposed to $26.7 \mathrm{eV}$ for graphite. Efforts were made to correlate the electrochemical behavior of the CMS electrodes and other HCs reported in publications to their local 
structures in terms of the $\mathrm{I}_{\mathrm{D}} / \mathrm{I}_{\mathrm{G}}$ and $\mathrm{d}_{002}$ parameters. Accordingly, sodium ion insertion is optimum in HCs synthesized in the temperature range from 1200 to 1600 for which the $\mathrm{I}_{\mathrm{D}} / \mathrm{I}_{\mathrm{G}}$ ratio is greater than 1 and the $\mathrm{d}_{002}$ spacing varies from 3.7 to $3.9 \AA$ A. Electrochemical testing in half-cells showed that the CMS-1500 was most promising as it had an optimum balance of the degree of graphitization (as evidenced by $\mathrm{I}_{\mathrm{D}} / \mathrm{I}_{\mathrm{G}} \sim 1.27$ ) and a $\mathrm{d}_{002}$ spacing of $3.7 \AA$, which is suitable for sodium ion insertion, and most of its capacity originated from the flat voltage-capacity regime of the galvanostatic curves. The iCE for CMS-1200, CMS-1400, and CMS-1500 was 69, 78 , and $85-89 \%$ (depending on the rate of cycling), respectively. Thus, further studies were focused on the CMS-1500 sample.

In general, the reversible capacity of CMS-1500 at the slowest rate was about $300 \mathrm{mAh} \mathrm{g}^{-1}$, with a coulombic efficiency of above $99 \%$. This is in good agreement to the best performing HC materials reported in the current-state-of-the-art literature. The rate of $\mathrm{Na}^{+}$ insertion was investigated for currents ranging from 20 to $1280 \mathrm{~mA} \mathrm{~g}^{-1}$. Characteristic of HC electrodes, the galvanostatic charge-discharge curves indicated that principally two different mechanisms are operative in the charge storage process: a sloping voltage profile ranging from 0.1 to $1.2 \mathrm{~V}$ and a nearly flat profile ranging from 0.005 to $0.1 \mathrm{~V}$ versus $\mathrm{Na}^{+} / \mathrm{Na}$. The majority of charge storage occurs within the flat voltage region at low cycling currents. However, the contribution of the sloping voltage region increased and became dominant as the cycling current increased beyond $80 \mathrm{~mA} \mathrm{~g}^{-1}$. Based on three-electrode half-cell studies, the counter electrode exhibited increasingly higher overpotential for sodium stripping and plating with increasing applied currents, while the overpotential at the HC electrode measured versus a separate sodium metal reference changed slightly and no capacity loss was observed. In fact, underpotential plating of sodium became more favorable as compared with sodium ion insertion as the cycling currents increased. The results also indicated that rate performance was ultimately limited by the poor mass transport characteristics of sodium ions in disordered carbon structure. The main reason why similar behavior is not observed in 2-electrode half-cells is because of the predominant ohmic drop at the sodium metal electrode, as indicated by EIS measurements, which reduced the effective voltage window. This fact must be considered when investigating the rate performance of HCs in full-cell SIBs. The performance of the HC was also evaluated using the PW electrode as a source of sodium ions for which a stable capacity of $97 \mathrm{mAh} \mathrm{g}^{-1}$ was obtained with an output voltage about $3 \mathrm{~V}$ vs. $\mathrm{Na}^{+} / \mathrm{Na}$. Further improvement to the electrolyte system is expected to improve battery performance.

\section{Data availability statement}

The raw and processed data required to reproduce these findings cannot be shared openly at this time, but readers can contact the authors to get access to the data in private.

\section{Credit author statement}

Habtom Desta Asfaw: Conceptualization, Methodology, Investigation, Writing-Original draft preparation, Writing-Review and Editing Cheuk-Wai Tai: Investigation, Writing-Review and Editing Mario Valvo Investigation, Writing-Review and Editing Reza Younesi: Resources, Writing-Review and Editing.

\section{Declaration of competing interest}

The authors declare that they have no known competing financial interests or personal relationships that could have appeared to influence the work reported in this paper.

\section{Acknowledgments}

The authors acknowledge financial support from StandUp for Energy and The Swedish Energy Agency. HDA was sponsored by a research grant from the Stiftelsen ÅForsk (grant number 19-650). The Myfab-LIMS (Uppsala University) and the Knut and Alice Wallenberg Foundation (Stockholm University) are acknowledged for the provision of electron microscopy facilities used to collect the SEM and TEM images, respectively. CWT acknowledges funding from the Swedish Research Council (project nr. 2018-05260). Special thanks go to Dr. Ronnie Mogensen (Uppsala University) for the fruitful discussion regarding the electrochemistry of Prussian white materials and Antonia Kotronia (Uppsala University) for collecting the FTIR data of hard carbon.

\section{Appendix A. Supplementary data}

Supplementary data to this article can be found online at https://doi.org/10.1016/j.mtener.2020.100505.

\section{References}

[1] E. Fan, L. Li, Z. Wang, J. Lin, Y. Huang, Y. Yao, R. Chen, F. Wu, Sustainable recycling technology for $\mathrm{Li}$-ion batteries and beyond: challenges and future prospects, Chem. Rev. 120 (14) (2020) 7020-7063, https://doi.org/10.1021/ acs.chemrev.9b00535.

[2] A. El Kharbachi, O. Zavorotynska, M. latroche, F. cuevas, V. Yartys, M. Fichtner, Exploits, advances and challenges benefiting beyond Li-ion battery technologies, J. Alloys Compd. 817 (2020) 153261.

[3] C. Vaalma, D. Buchholz, M. Weil, S. Passerini, A cost and resource analysis of sodium-ion batteries, Nature Reviews Materials 3 (4) (2018) 18013.

[4] B.L. Ellis, L.F. Nazar, Sodium and sodium-ion energy storage batteries, Curr. Opin. Solid State Mater. Sci. 16 (4) (2012) 168-177.

[5] M. Dahbi, N. Yabuuchi, K. Kubota, K. Tokiwa, S. Komaba, Negative electrodes for Na-ion batteries, Phys. Chem. Chem. Phys. 16 (29) (2014) 15007-15028.

[6] L. Li, Y. Zheng, S. Zhang, J. Yang, Z. Shao, Z. Guo, Recent progress on sodium ion batteries: potential high-performance anodes, Energy Environ. Sci. 11 (9) (2018) 2310-2340.

[7] K. Kubota, S. Komaba, Review-practical issues and future perspective for Naion batteries, J. Electrochem. Soc. 162 (14) (2015) A2538-A2550.

[8] Y. Liu, B.V. Merinov, W.A. Goddard, Origin of low sodium capacity in graphite and generally weak substrate binding of $\mathrm{Na}$ and $\mathrm{Mg}$ among alkali and alkaline earth metals, Proc. Natl. Acad. Sci. Unit. States Am. 113 (14) (2016) 3735.

[9] G. Yoon, H. Kim, I. Park, K. Kang, Conditions for reversible Na intercalation in graphite: theoretical studies on the interplay among guest ions, solvent, and graphite host, Advanced Energy Materials 7 (2) (2017) 1601519.

[10] D.P. DiVincenzo, E.J. Mele, Cohesion and structure in stage-1 graphite intercalation compounds, Phys. Rev. B 32 (4) (1985) 2538-2553.

[11] J.O. Besenhard, The electrochemical preparation and properties of ionic alkali metal-and NR4-graphite intercalation compounds in organic electrolytes, Carbon 14 (2) (1976) 111-115.

[12] I.A. Udod, H.B. Orman, V.K. Genchel, The sodium-graphite system under highpressure conditions: the comparison with the lithium-graphite system, Carbon 32 (1) (1994) 101-106.

[13] P. Ge, M. Fouletier, Electrochemical intercalation of sodium in graphite, Solid State Ionics 28-30 (1988) 1172-1175.

[14] B. Jache, P. Adelhelm, Use of graphite as a highly reversible electrode with superior cycle life for sodium-ion batteries by making use of Co-intercalation phenomena, Angew. Chem. Int. Ed. 53 (38) (2014) 10169-10173.

[15] H. Kim, J. Hong, Y.-U. Park, J. Kim, I. Hwang, K. Kang, Sodium storage behavior in natural graphite using ether-based electrolyte systems, Adv. Funct. Mater. 25 (4) (2015) 534-541.

[16] Z.-L. Xu, G. Yoon, K.-Y. Park, H. Park, O. Tamwattana, S. Joo Kim, W.M. Seong, K. Kang, Tailoring sodium intercalation in graphite for high energy and power sodium ion batteries, Nat. Commun. 10 (1) (2019) 2598.

[17] Z.-L. Xu, J. Park, G. Yoon, H. Kim, K. Kang, Graphitic carbon materials for advanced sodium-ion batteries, Small Methods 3 (4) (2019) 1800227.

[18] D. Ginderow, R. Setton, New graphite lamellar compounds, Carbon 6 (1) (1968) 81-83.

[19] H. Kim, J. Hong, G. Yoon, H. Kim, K.-Y. Park, M.-S. Park, W.-S. Yoon, K. Kang, Sodium intercalation chemistry in graphite, Energy Environ. Sci. 8 (10) (2015) 2963-2969.

[20] J. Maibach, F. Jeschull, D. Brandell, K. Edström, M. Valvo, Surface layer evolution on graphite during electrochemical sodium-tetraglyme Co-intercalation, ACS Appl. Mater. Interfaces 9 (14) (2017) 12373-12381.

[21] D.A. Stevens, J.R. Dahn, High capacity anode materials for rechargeable sodium-ion batteries, J. Electrochem. Soc. 147 (4) (2000) 1271. 
[22] B. Xiao, T. Rojo, X. Li, Hard carbon as sodium-ion battery anodes: progress and challenges, ChemSusChem 12 (1) (2019) 133-144.

[23] E. Irisarri, A. Ponrouch, M.R. Palacin, Review—hard carbon negative electrode materials for sodium-ion batteries, J. Electrochem. Soc. 162 (14) (2015) A2476-A2482.

[24] A. Gomez-Martin, J. Martinez-Fernandez, M. Ruttert, M. Winter, T. Placke, J. Ramirez-Rico, Correlation of structure and performance of hard carbons as anodes for sodium ion batteries, Chem. Mater. 31 (18) (2019) 7288-7299.

[25] J. Jin, Z.-q. Shi, C.-y. Wang, Electrochemical performance of electrospun carbon nanofibers as free-standing and binder-free anodes for sodium-ion and lithium-ion batteries, Electrochim. Acta 141 (2014) 302-310.

[26] J. Jin, B.-j. Yu, Z.-q. Shi, C.-y. Wang, C.-b. Chong, Lignin-based electrospun carbon nanofibrous webs as free-standing and binder-free electrodes for sodium ion batteries, J. Power Sources 272 (2014) 800-807.

[27] S. Komaba, W. Murata, T. Ishikawa, N. Yabuuchi, T. Ozeki, T. Nakayama, A. Ogata, K. Gotoh, K. Fujiwara, Electrochemical Na insertion and solid electrolyte interphase for hard-carbon electrodes and application to Na-ion batteries, Adv. Funct. Mater. 21 (20) (2011) 3859-3867.

[28] D.A. Stevens, J.R. Dahn, The mechanisms of lithium and sodium insertion in carbon materials, J. Electrochem. Soc. 148 (8) (2001) A803.

[29] C. Bommier, W. Luo, W.-Y. Gao, A. Greaney, S. Ma, X. Ji, Predicting capacity of hard carbon anodes in sodium-ion batteries using porosity measurements, Carbon 76 (2014) 165-174.

[30] A. Beda, P.-L. Taberna, P. Simon, C. Matei Ghimbeu, Hard carbons derived from green phenolic resins for Na-ion batteries, Carbon 139 (2018) 248-257.

[31] B. Zhang, C.M. Ghimbeu, C. Laberty, C. Vix-Guterl, J.-M. Tarascon, Correlation between microstructure and Na storage behavior in hard carbon, Advanced Energy Materials 6 (1) (2016) 1501588.

[32] Y. Li, S. Xu, X. Wu, J. Yu, Y. Wang, Y.-S. Hu, H. Li, L. Chen, X. Huang, Amorphous monodispersed hard carbon micro-spherules derived from biomass as a high performance negative electrode material for sodium-ion batteries, J. Mater. Chem. 3 (1) (2015) 71-77.

[33] Z. Li, C. Bommier, Z.S. Chong, Z. Jian, T.W. Surta, X. Wang, Z. Xing, J.C. Neuefeind, W.F. Stickle, M. Dolgos, P.A. Greaney, X. Ji, Mechanism of Naion storage in hard carbon anodes revealed by heteroatom doping, Advanced Energy Materials 7 (18) (2017) 1602894.

[34] D. Zhang, J. Zhao, C. Feng, R. Zhao, Y. Sun, T. Guan, B. Han, N. Tang, J. Wang, K. Li, J. Qiao, J. Zhang, Scalable synthesis of hierarchical macropore-rich activated carbon microspheres assembled by carbon nanoparticles for high rate performance supercapacitors, J. Power Sources 342 (2017) 363-370.

[35] Z. Jian, Z. Xing, C. Bommier, Z. Li, X. Ji, Hard carbon microspheres: potassiumion anode versus sodium-ion anode, Advanced Energy Materials 6 (3) (2016) 1501874.

[36] W. Xiong, M. Liu, L. Gan, Y. Lv, Y. Li, L. Yang, Z. Xu, Z. Hao, H. Liu, L. Chen, A novel synthesis of mesoporous carbon microspheres for supercapacitor electrodes, J. Power Sources 196 (23) (2011) 10461-10464.

[37] Q. Wang, H. Li, L. Chen, X. Huang, Monodispersed hard carbon spherules with uniform nanopores, Carbon 39 (14) (2001) 2211-2214.

[38] H. Tang, M. Wang, T. Lu, L. Pan, Porous carbon spheres as anode materials for sodium-ion batteries with high capacity and long cycling life, Ceram. Int. 43 (5) (2017) 4475-4482.

[39] F.P. Hu, Z. Wang, Y. Li, C. Li, X. Zhang, P.K. Shen, Improved performance of Pd electrocatalyst supported on ultrahigh surface area hollow carbon spheres for direct alcohol fuel cells, J. Power Sources 177 (1) (2008) 61-66.

[40] Q. Wang, F. Cao, Q. Chen, C. Chen, Preparation of carbon micro-spheres by hydrothermal treatment of methylcellulose sol, Mater. Lett. 59 (28) (2005) 3738-3741.

[41] A.A. Deshmukh, S.D. Mhlanga, N.J. Coville, Carbon spheres, Mater. Sci. Eng. R Rep. 70 (1) (2010) 1-28.

[42] J. Liu, S.Z. Qiao, H. Liu, J. Chen, A. Orpe, D. Zhao, G.Q. Lu, Extension of the stöber method to the preparation of monodisperse resorcinol-formaldehyde resin polymer and carbon spheres, Angew. Chem. Int. Ed. 50 (26) (2011) 5947-5951.

[43] L. Frusteri, C. Cannilla, G. Bonura, A.L. Chuvilin, S. Perathoner, G. Centi, F. Frusteri, Carbon microspheres preparation, graphitization and surface functionalization for glycerol etherification, Catal. Today 277 (2016) 68-77.

[44] R. Alcántara, P. Lavela, G.F. Ortiz, J.L. Tirado, Carbon microspheres obtained from resorcinol-formaldehyde as high-capacity electrodes for sodium-ion batteries, Electrochem. Solid State Lett. 8 (4) (2005) A222-A225.

[45] L.K. Gil-Herrera, Á. Blanco, B.H. Juárez, C. López, Seeded synthesis of monodisperse core-shell and hollow carbon spheres, Small 12 (32) (2016) 4357-4362.

[46] X. Ma, F. Xu, L. Chen, Y. Zhang, Z. Zhang, J. Qian, Y. Qian, Easy nickel substrateassisted growth of uniform carbon microspheres and their spectroscopic properties, Carbon 44 (13) (2006) 2861-2864.

[47] X. Wang, J. Guo, X. Yang, B. Xu, Monodisperse carbon microspheres synthesized from asphaltene, Mater. Chem. Phys. 113 (2) (2009) 821-823.

[48] S. Wang, R. Wang, Y. Zhang, D. Jin, L. Zhang, Scalable and sustainable synthesis of carbon microspheres via a purification-free strategy for sodium-ion capacitors, J. Power Sources 379 (2018) 33-40.

[49] M. Sevilla, A.B. Fuertes, Chemical and structural properties of carbonaceous products obtained by hydrothermal carbonization of saccharides, Chem. Eur J. 15 (16) (2009) 4195-4203.
[50] M. Sevilla, A.B. Fuertes, The production of carbon materials by hydrothermal carbonization of cellulose, Carbon 47 (9) (2009) 2281-2289.

[51] L. Wang, J. Song, R. Qiao, L.A. Wray, M.A. Hossain, Y.-D. Chuang, W. Yang, Y. Lu, D. Evans, J.-J. Lee, S. Vail, X. Zhao, M. Nishijima, S. Kakimoto, J.B. Goodenough, Rhombohedral prussian white as cathode for rechargeable sodium-ion batteries, J. Am. Chem. Soc. 137 (7) (2015) 2548-2554.

[52] W.R. Brant, R. Mogensen, S. Colbin, D.O. Ojwang, S. Schmid, L. Häggström, T. Ericsson, A. Jaworski, A.J. Pell, R. Younesi, Selective Control of composition in prussian white for enhanced material properties, Chem. Mater. 31 (18) (2019) 7203-7211.

[53] P. Ewels, T. Sikora, V. Serin, C.P. Ewels, L. Lajaunie, A complete overhaul of the electron energy-loss spectroscopy and X-ray absorption spectroscopy Database: eelsdb.eu, Microsc. Microanal. 22 (3) (2016) 717-724.

[54] C.L. Losq, Rampy: a Python library for processing spectroscopic (IR, Raman, XAS.) data, rampy-0.4.3.. http://doi.org/10.5281/zenodo.1168730, 2018.

[55] R.C. Fuson, C.H. McKeever, Chloromethylation of aromatic compounds, Org. React. (2011) 63-90.

[56] S. Mulik, C. Sotiriou-Leventis, N. Leventis, Time-efficient acid-catalyzed synthesis of Resorcinol-Formaldehyde aerogels, Chem. Mater. 19 (25) (2007) 6138-6144.

[57] George Socrates. Infrared and Raman characteristic group frequencies: tables and charts, 3rd, John Wiley \& Sons, 2004.

[58] C.A. Schneider, W.S. Rasband, K.W. Eliceiri, NIH Image to Image]: 25 years of image analysis, Nat. Methods 9 (7) (2012) 671-675.

[59] Y. Cao, L. Xiao, M.L. Sushko, W. Wang, B. Schwenzer, J. Xiao, Z. Nie, L.V. Saraf, Z. Yang, J. Liu, Sodium ion insertion in hollow carbon nanowires for battery applications, Nano Lett. 12 (7) (2012) 3783-3787.

[60] H. Daniels, R. Brydson, B. Rand, A. Brown, Investigating carbonization and graphitization using electron energy loss spectroscopy (EELS) in the transmission electron microscope (TEM), Phil. Mag. 87 (27) (2007) 4073-4092.

[61] H. Hirai, Chapter 15-electron energy-loss spectroscopy and its applications to characterization of carbon materials, in: E.-i. Yasuda, M. Inagaki, K. Kaneko, M. Endo, A. Oya, Y. Tanabe (Eds.), Carbon Alloys, Elsevier Science, Oxford, 2003, pp. 239-256.

[62] Ray F. Egerton. Electron energy-loss spectroscopy in the electron microscope, 3rd, Springer Science \& Business Media, 2011.

[63] Z.-1. Zhang, R. Brydson, Z. Aslam, S. Reddy, A. Brown, A. Westwood, B. Rand, Investigating the structure of non-graphitising carbons using electron energy loss spectroscopy in the transmission electron microscope, Carbon 49 (15) (2011) 5049-5063.

[64] A.C. Ferrari, Raman spectroscopy of graphene and graphite: disorder, electron-phonon coupling, doping and nonadiabatic effects, Solid State Commun. 143 (1) (2007) 47-57.

[65] A.C. Ferrari, J. Robertson, Interpretation of Raman spectra of disordered and amorphous carbon, Phys. Rev. B 61 (20) (2000) 14095-14107.

[66] Y. Wang, D.C. Alsmeyer, R.L. McCreery, Raman spectroscopy of carbon materials: structural basis of observed spectra, Chem. Mater. 2 (5) (1990) 557-563.

[67] L.G. Cançado, A. Jorio, M.A. Pimenta, Measuring the absolute Raman cross section of nanographites as a function of laser energy and crystallite size, Phys. Rev. B 76 (6) (2007), 064304.

[68] F. Tuinstra, J.L. Koenig, Raman spectrum of graphite, J. Chem. Phys. 53 (3) (1970) 1126-1130.

[69] M. Carboni, J. Manzi, A.R. Armstrong, J. Billaud, S. Brutti, R. Younesi, Analysis of the solid electrolyte interphase on hard carbon electrodes in sodium-ion batteries, ChemElectroChem 6 (6) (2019) 1745-1753.

[77] J. Fondard, E. Irisarri, C. Courrèges, M.R. Palacin, A. Ponrouch, R. Dedryvère, SEI composition on hard carbon in Na-ion batteries after long cycling: influence of salts (NaPF6, NaTFSI) and additives (FEC, DMCF), J. Electrochem. Soc. 167 (7) (2020), 070526.

[78] D.I. Iermakova, R. Dugas, M.R. Palacín, A. Ponrouch, On the comparative stability of $\mathrm{Li}$ and $\mathrm{Na}$ metal anode interfaces in conventional alkyl carbonate electrolytes, J. Electrochem. Soc 162 (13) (2015) A7060-A7066.

[79] T. Hosaka, S. Muratsubaki, K. Kubota, H. Onuma, S. Komaba, Potassium metal as reliable reference electrodes of nonaqueous potassium cells, J. Phys. Chem. Lett. 10 (12) (2019) 3296-3300.

[80] K. Wang, Y. Jin, S. Sun, Y. Huang, J. Peng, J. Luo, Q. Zhang, Y. Qiu, C. Fang, J. Han, Low-cost and high-performance hard carbon anode materials for sodium-ion batteries, ACS Omega 2 (4) (2017) 1687-1695.

[81] Q. Wang, X. Zhu, Y. Liu, Y. Fang, X. Zhou, J. Bao, Rice husk-derived hard carbons as high-performance anode materials for sodium-ion batteries, Carbon 127 (2018) 658-666.

[82] X. Li, X. Zeng, T. Ren, J. Zhao, Z. Zhu, S. Sun, Y. Zhang, The transport properties of sodium-ion in the low potential platform region of oatmeal-derived hard carbon for sodium-ion batteries, J. Alloys Compd. 787 (2019) 229-238.

[83] L. Xiao, Y. Cao, W.A. Henderson, M.L. Sushko, Y. Shao, J. Xiao, W. Wang, M.H. Engelhard, Z. Nie, J. Liu, Hard carbon nanoparticles as high-capacity, high-stability anodic materials for Na-ion batteries, Nanomater. Energy 19 (2016) 279-288.

[84] Y. Huang, Y. Zheng, X. Li, F. Adams, W. Luo, Y. Huang, L. Hu, Electrode materials of sodium-ion batteries toward practical application, ACS Energy Letters 3 (7) (2018) 1604-1612. 